Article

\title{
Injured Achilles Tendons Treated with Adipose-Derived Stem Cells Transplantation and GDF-5
}

\author{
Andrea Aparecida de Aro ${ }^{1,2, *}$, Giane Daniela Carneiro ${ }^{1}$, Luis Felipe R. Teodoro ${ }^{1}$, \\ Fernanda Cristina da Veiga ${ }^{3}$, Danilo Lopes Ferrucci ${ }^{1}$, Gustavo Ferreira Simões ${ }^{1}$, \\ Priscyla Waleska Simões ${ }^{4}$ (iD, Lúcia Elvira Alvares ${ }^{3}$, Alexandre Leite R. de Oliveira ${ }^{1}$, \\ Cristina Pontes Vicente ${ }^{1}$, Caio Perez Gomes 5 (iD), João Bosco Pesquero 5 (iD, \\ Marcelo Augusto M. Esquisatto ${ }^{2}$, Benedicto de Campos Vidal ${ }^{1}$ and Edson Rosa Pimentel ${ }^{1}$ \\ 1 Department of Structural and Functional Biology, Institute of Biology, State University of \\ Campinas-UNICAMP, Charles Darwin, s/n, CP 6109, 13083-970 Campinas, SP, Brazil; \\ gianedc@gmail.com (G.D.C.); teo.luisfelipe@gmail.com (L.F.R.T.); daniloferrucci@yahoo.com.br (D.L.F.); \\ gfsimoes2@gmail.com (G.F.S.); alroliv@unicamp.br (A.L.R.d.O.); crpvicente@gmail.com (C.P.V.); \\ camposvi@unicamp.br (B.d.C.V.); pimentel@unicamp.br (E.R.P.) \\ 2 Biomedical Sciences Graduate Program, Herminio Ometto University Center-UNIARARAS, \\ 13607-339 Araras, SP, Brazil; marcelosquisatto@uniararas.br \\ 3 Department of Biochemistry and Tissue Biology, Institute of Biology, State University of \\ Campinas-UNICAMP, Charles Darwin, s/n, CP 6109, 13083-970 Campinas, SP, Brazil; \\ fernandaveiga6@gmail.com (F.C.d.V.); lealvare@unicamp.br (L.E.A.) \\ 4 Engineering, Modeling and Applied Social Sciences Center (CECS), Biomedical Engineering Graduate \\ Program (PPGEBM), Universidade Federal do ABC (UFABC), Alameda da Universidade s/n, \\ 09606-045 São Bernardo do Campo, SP, Brazil; pritsimoes@gmail.com \\ 5 Department of Biophysics, Federal University of Sao Paulo-Unifesp, Pedro de Toledo, 699, \\ 04039-032 Sao Paulo, SP, Brazil; caiopgomes@hotmail.com (C.P.G.); jbpesquero@unifesp.br (J.B.P.) \\ * Correspondence: andreaaro80@gmail.com; Tel.: +55-19-3543-1423
}

Received: 19 July 2018; Accepted: 23 August 2018; Published: 31 August 2018

\begin{abstract}
Tendon injuries represent a clinical challenge in regenerative medicine because their natural repair process is complex and inefficient. The high incidence of tendon injuries is frequently associated with sports practice, aging, tendinopathies, hypertension, diabetes mellitus, and the use of corticosteroids. The growing interest of scientists in using adipose-derived mesenchymal stem cells (ADMSC) in repair processes seems to be mostly due to their paracrine and immunomodulatory effects in stimulating specific cellular events. ADMSC activity can be influenced by GDF-5, which has been successfully used to drive tenogenic differentiation of ADMSC in vitro. Thus, we hypothesized that the application of ADMSC in isolation or in association with GDF-5 could improve Achilles tendon repair through the regulation of important remodeling genes expression. Lewis rats had tendons distributed in four groups: Transected (T), transected and treated with ADMSC (ASC) or GDF-5 (GDF5), or with both (ASC+GDF5). In the characterization of cells before application, ADMSC expressed the positive surface markers, CD90 (90\%) and CD105 (95\%), and the negative marker, CD45 (7\%). ADMSC were also differentiated in chondrocytes, osteoblast, and adipocytes. On the 14th day after the tendon injury, GFP-ADMSC were observed in the transected region of tendons in the ASC and ASC+GDF5 groups, and exhibited and/or stimulated a similar genes expression profile when compared to the in vitro assay. ADMSC up-regulated Lox, Dcn, and Tgfb1 genes expression in comparison to T and ASC+GDF5 groups, which contributed to a lower proteoglycans arrangement, and to a higher collagen fiber organization and tendon biomechanics in the ASC group. The application of ADMSC in association with GDF-5 down-regulated Dcn, Gdf5, Lox, Tgfb1, Mmp2, and Timp2 genes expression, which contributed to a lower hydroxyproline concentration, lower collagen fiber organization, and to an improvement of the rats' gait $24 \mathrm{~h}$ after the injury.
\end{abstract}


In conclusion, although the literature describes the benefic effect of GDF- 5 for the tendon healing process, our results show that its application, isolated or associated with ADMSC, cannot improve the repair process of partial transected tendons, indicating the higher effectiveness of the application of ADMSC in injured Achilles tendons. Our results show that the application of ADMSC in injured Achilles tendons was more effective in relation to its association with GDF-5.

Keywords: repair; extracellular matrix; collagen; gait; biomechanics; gene expression

\section{Introduction}

Tendon injuries are very common and their natural repair process is extremely slow, complex, and inefficient due to their intrinsic hypocellularity and hypovascularity, representing a clinical challenge to orthopedists mainly because these injuries often respond poorly to treatment [1]. As reviewed by Zabrzyński et al. [2], the occurrence of tendon injuries is associated with sports, aging, tendinophaties, hypothyroidism, hypertension, diabetes mellitus, arthropathies, corticosteroids, vitamin $C$ deficiency, and others. Collagen fibers are the main component of the abundant extracellular matrix (ECM) of tendons, and with the proteoglycans (PG), the collagen fibers form a highly organized supramolecular structure, able to attend to the biomechanical demands on the tissue [3,4]. Particularly, small leucine-rich proteoglycans (SLRPs), such as decorin, fibromodulim, and biglycan, are the most abundant PG in tendons, with decorin representing $80 \%$ of the total proteoglycan content of the tissue [5]. SLRPs interact with the collagen fibrils, acting in the fibrillogenesis of collagen, and probably regulating the growth in diameter of these fibrils [6]. Besides the parallel bundles of predominantly type I collagen fibers and PG, non-collagenous glycoproteins, matrix metalloproteinases (MMP), growth factors, and cells also comprise elements of the tendons [5,7-9].

The specific mechanical tendon properties are directly related to the high organization of collagen bundles [10]. After injuries, the structural organization and composition of tendons are not completely restored, with a fibrous scar formation that can cause significant dysfunction and joint movement inability $[11,12]$. After the repair process, tendons become biomechanically weakened, making it more prone to re-rupture $[9,13]$. Clearly, new treatments are needed with the objective of improving tendon repair, considering that these injuries reach the population that is economically active, and that the use of cell therapy using mesenchymal stem cells (MSC) could be a good strategy.

Adult tissues are attractive MSC sources, which are characterized as undifferentiated cells, with mesodermal differentiation potential and self-renew and high proliferative capacities [14]. Adipose tissue is an alternative source of MSC that can be obtained by a less invasive method under local anesthesia, with little associated patient discomfort and in larger quantities as compared with bone marrow [15]. The effectiveness of adipose-derived mesenchymal stem cells (ADMSC) in regenerative medicine seems to be due to their paracrine effects that stimulate specific cellular events, like the growth factors and cytokines delivery [16], as well as their immunomodulatory effects to promote tendon regeneration [17]. Besides recruiting progenitor cells from some tissues, the ADMSC could also differentiate specific cells during tissue repair [18-20]. However, the literature is controversial about the effects of ADMSC transplantation during tendon repair. In some animal models, there was greater structural organization, biomechanical properties, density of collagen fibers, collagen types I and III genes expression, and growth factors synthesis as fibroblast growth factor (FGF), vascular endothelial growth factor (VEGF), and transforming growth factor (TGF- $\beta$ ) after ADMSC application in relation to untreated tendons [7,21-23]. Conversely, no differences were observed after this cellular therapy in the biomechanical parameters or collagen production $[7,17,23]$.

It is widely accepted that the control of stem cell activity is influenced by several different environmental factors [24], including growth factors [1]. To drive tenogenic ADMSC in in vitro differentiation, insulin like growth factor (IGF)- 1 or TGF- $\beta$ in a co-culture with primary tenocytes 
and growth differentiation factor-5 (GDF-5) have been used successfully $[19,20]$. GDF-5 belongs to the TGF- $\beta$ superfamily and it is known as cartilage-derived morphogenetic protein-1 (CDMP-1) and bone-derived morphogenetic protein-14 (BMP-14). Storm et al. [25] documented two other members of this superfamily, such as GDF-6 (BMP-13) and GDF-7 (BMP-12). GDF family members are also called bone-derived morphogenetic proteins (BMP) because they are found predominantly during the development of endochondral bones [26] and joint formation [27]. Wolfman et al. [28] demonstrated that the three members of BMP induce the formation of connective tissue rich in collagen I, with an important role in the process of tendon healing [29,30]. From this study, the BMP ceased to be considered as only chondrogenic and osteogenic factors, as suggested by the name, and were considered tendinogenic factors. Forslund and colleagues [30], who showed increased Achilles tendon resistance after rupture, reported the initial success of BMP-12, -13, and -14 in tendon healing. In a study of Chhabra et al. [31], mice deficient in the GDF-5 gene had a poor healing process, with lesser structural organization and decreased biomechanical properties of tendons, evidencing the importance of this growth factor during tendon repair processes. Currently, cell therapy using the ADMSC associated with the exogenous application of growth factors represents a great potential in the process of tendon repair. Despite promising studies in animals, no treatment associated with the application of ADMSC in tendon injuries has been used in clinics due to the lack of knowledge on molecular aspects involving those therapies.

The objective of the present study was to test the hypothesis that the application of ADMSC in isolation or associated with GDF- 5 could improve Achilles tendon repair. The use of GDF- 5 was based on the literature that demonstrates its importance during tendon healing and the role of GDF- 5 in modulating ADMSC tenogenic differentiation in vitro. Thus, the down- or up-regulation of remodeling genes expression in response to ADMSC and GDF-5 application were analyzed, and the involvement of those genes in the restoration of the structural, biomechanical, and functional properties of Achilles tendons after partial transection.

\section{Materials and Methods}

\subsection{In Vitro Experiments}

\subsubsection{Isolation of ADMSC and Cell Culture}

The procedure was done according to Yang et al. [32] with some modifications. Adipose tissue was obtained from the inguinal region of 10 male Lewis rats between 90-120 days. Adipose tissue was cut and washed in Dulbecco's modified phosphate buffered saline solution (DMPBS Flush without calcium and magnesium) containing $2 \%$ streptomycin/penicillin to remove contaminating blood cells. Then, $0.2 \%$ collagenase (Sigma-Aldrich ${ }^{\circledR}$ Inc., Saint Louis, MO, USA) was added to degradation of the $\mathrm{ECM}$ and the solution was maintained at $37^{\circ} \mathrm{C}$ under gentle stirring for $1 \mathrm{~h}$ to separate the stromal cells from primary adipocytes. Dissociated tissue was filtered using cell strainers $(40 \mu \mathrm{m})$ and the inactivation of collagenase was then done by the addition of an equal volume of Dulbecco's modified Eagle's medium (DMEM) supplemented with $15 \%$ fetal bovine serum (FBS), followed by centrifugation at $1800 \mathrm{rpm}$ for $10 \mathrm{~min}$. The suspending portion containing lipid droplets was discarded and the pellet was resuspended in DMEM (containing $50 \mathrm{mg} / \mathrm{L}$ penicillin and $50 \mathrm{mg} / \mathrm{L}$ streptomycin) with $15 \% \mathrm{FBS}$, and transferred to $25 \mathrm{~cm}^{2}$ flasks for 48 hours. After confluence, cells were transferred to $75 \mathrm{~cm}^{2}$ flasks (1st passage). The medium was replaced after $48 \mathrm{~h}$ and then every 3 days. Cultures were maintained at $37^{\circ} \mathrm{C}$ with $5 \% \mathrm{CO}_{2}$ until the 5 th passage (5P), always at up to $80 \%$ confluency.

\subsubsection{Flow Cytometry}

ADMSC at 5P $(n=4)$ were trypsinized and centrifuged at $1800 \mathrm{rpm}$ for $10 \mathrm{~min}$, and counted using the Neubauer chamber. $1 \times 10^{6}$ ADMSC were resuspended in $200 \mathrm{uL}$ of DMPBS Flush with $2 \%$ BSA (bovine serum albumin). For the immunophenotypic panel, the following antibodies were used: 
CD90-APC, CD105-PE, and CD45-APC double conjugated (eBioscience ${ }^{\circledR}$ Inc., San Diego, CA, USA) were diluted 1:200 and incubated for $40 \mathrm{~min}$ at room temperature. Subsequently, ADMSC were washed twice with $500 \mu \mathrm{L}$ of DMPBS Flush and centrifuged at $2000 \mathrm{rpm}$ for $7 \mathrm{~min}$. The ADMSC were resuspended in DMPBS Flush with 2\% BSA, followed by the flow cytometry analysis.

\subsubsection{In Vitro Differentiation Potential of ADMSC}

Using different media for each type of differentiation, ADMSC (5P) were cultured $\left(2 \times 10^{4}\right.$ cells $)$ according to Yang et al. [32] with some modifications. Osteogenic differentiation $(n=3)$ : DMEM supplemented with $10 \% \mathrm{FBS}, 0.1 \mu \mathrm{M}$ dexamethasone, $200 \mu \mathrm{M}$ ascorbic acid, and $10 \mathrm{mM} \beta$-glycerol phosphate. Adipogenic differentiation $(n=3)$ : DMEM supplemented with $10 \% \mathrm{FBS}, 1 \mu \mathrm{mol} / \mathrm{L}$ dexamethasone, $50 \mu \mathrm{mol} / \mathrm{L}$ indomethacin, $0.5 \mathrm{mM}$ 3-isobutyl-1-methyl-xanthine, and $10 \mu \mathrm{M}$ insulin. Condrogenic differentiation $(n=3)$ : DMEM supplemented with $10 \% \mathrm{FBS}$, acid free $15 \mathrm{mM}$ HEPES, $6.25 \mu \mathrm{g} / \mathrm{mL}$ insulin, $10 \mathrm{ng} / \mathrm{mL}$ TGF- $\beta 1$, and $50 \mathrm{nM}$ AsAP. Cultures were maintained at $37^{\circ} \mathrm{C}$ with $5 \%$ $\mathrm{CO}_{2}$, and the complete mediums were replaced twice a week. At the end of four weeks, cells were fixed with $4 \%$ paraformaldehyde for 20 min and stained with $2 \%$ Alizarin Red S (pH 4.1) during 5 min for calcium detection, with $0.025 \%$ Toluidine blue in Mcllvaine buffer $(0.03 \mathrm{M}$ citric acid, $0.04 \mathrm{M}$ sodium phosphate dibasic, $\mathrm{pH} 4.0$ ) during $10 \mathrm{~min}$ for proteoglycans detection, and with $1 \%$ Sudan IV during $5 \mathrm{~min}$ to show lipid droplets. Samples were imaged on the Axiovert S100 (ZEISS) inverted microscope.

\subsubsection{Cell Viability}

Flasks of $75 \mathrm{~cm}^{2}$ with ADMSC in 5P $(n=3)$ were trypsinized and centrifuged at $1800 \mathrm{rpm}$ for $10 \mathrm{~min}$. The pellet obtained from each flasks was resuspended in $1 \mathrm{~mL}$ of DMPBS Flush. Then, an aliquot of $10 \mu \mathrm{L}$ of each culture was stained with $0.4 \%$ Trypan Blue, and the ADMSC were placed for analysis in the Countess II FL (Life Technologies ${ }^{\circledR}$ Inc., Carlsbad, CA, USA) equipment for cell concentration and viability measurements.

\subsubsection{Contrast by Differential Interference (DIC)}

For the birefringence analyses of nuclei, ADMSC (5P) in culture $(n=3)$ were stained with $0.025 \%$ toluidine blue solution in $0.1 \mathrm{M}$ Mcllvaine phosphate buffer at $\mathrm{pH} 4.3$ for $30 \mathrm{~min}$, followed by analyses in the Olympus BX-51 (Olympus America, Center Vallery, PA, USA) polarizing microscope equipped with a Q-color 5 camera (Olympus America), and using the Image Pro-plus v.6.3 software for Windows ${ }^{\mathrm{TM}}$ (Media Cybernetics, Silver Spring, MD, USA) $[4,33,34]$. With the microscope and the software, it is possible to carry out analysis of DIC and the anisotropic properties, both individually and in combination [34]. DIC observations were performed after addition of the two condenser's Wollaston prisms in the light path. With DIC-PLM, the optical path differences in samples can be detected through the sliding of another Wollaston prism that is positioned under the analyzer. The resulting colors in the sample are compared with the colors in a Michel-Lévy chart.

\subsubsection{Real Time-PCR Array for Analysis of ADMSC Gene Expression}

For the total RNA extraction of the ADMSC (5P) using Trizol ${ }^{\circledR}$ reagent, Invitrogen, Carlsbad, CA, USA, three different cultures were analyzed. A spectrophotometer (NanoDrop ${ }^{\circledR}$ ND-1000, Thermo Fisher Scientific ${ }^{\circledR}$, Waltham, MA, USA) was used to quantify the RNA in each sample by determining the absorbance ratio at 260 and $280 \mathrm{~nm}$. $0.5 \mu \mathrm{g}$ from the total extracted RNA of each sample was used for the synthesis of cDNA using the RT ${ }^{2}$ First Strand Kit $\left(\right.$ QIAGEN ${ }^{\circledR}$, Hilden, Germany) and thermocycler Mastercycler Pro (Eppendorf ${ }^{\circledR}$, Hamburg, Germany), also following the manufacturer's instructions. The cDNA was frozen at $-20{ }^{\circ} \mathrm{C}$ until tested. The RT-PCR array reaction was performed using the $\mathrm{RT}^{2}$ Profiler PCR Arrays (A format) kit in combination with the $\mathrm{RT}^{2}$ SYBR Green Mastermixes (QIAGEN ${ }^{\circledR}$, Hilden, Germany) on the thermocycler apparatus 7300 (ABI Applied Biosystems ${ }^{\circledR}$, Foster City, CA, USA), following the manufacturer's instructions. For each culture sample, three types of reaction controls were used: 
1. Positive PCR control; 2. Reverse transcriptase control; and 3. Control for contamination of rat genomic DNA. The Glyceraldehyde-3-phosphate dehydrogenase (Gapdh, NM_017008) was used as an endogenous control for each sample. The following genes were analyzed (QIAGEN ${ }^{\circledR}$ ): Scleraxis (Scx, NM_001130508); Tenomodulin (Tnmd, NM_022290); Tumor necrosis factor (TNF superfamily, member 2) (Tnf, NM_012675); Interleukin 1 beta (II1b, NM_031512); Transforming growth factor, beta 1 (Tgfb1, NM_021578); Matrix metallopeptidase 2 (Mmp2, NM_031054); Matrix metallopeptidase 9 (Mmp9, NM_031055); Matrix metallopeptidase 8 (Mmp8, NM_022221); TIMP metallopeptidase inhibitor 2 (Timp2, NM_021989); Decorin (Dcn, NM_024129); Lysyl oxidase (Lox, NM_017061); and Growth differentiation factor 5 (Gdf5, XM_001066344). Reactions were made in a single cDNA pipetting for each gene, including the endogenous control. $\triangle \mathrm{CT}$ values were obtained by the difference between the $\mathrm{CT}$ values of the target genes and the Gapdh gene. The $2^{-\Delta C T}$ method [35] was used to calculate the gene expression for each target gene.

\subsection{In Vivo Experiments}

\subsubsection{Experimental Groups}

A total of 110 male Lewis rats (120-day-old), with free access to food and water, were divided into 5 experimental groups (22 animals for each group): Normal (N): Rats with tendons without transection; Transected (T): Rats with partially transected tendons and treated with topical application of DMPBS Flush in the transected region; Mesenchymal stem cells derived from adipose tissue (ASC): Rats with transected tendons with subsequent transplant of ADMSC $\left(3.7 \times 10^{5}\right.$ cells $)$ in the transected region; GDF-5 (GDF5): Rats with transected tendons and treated with topical application of DMPBS Flush in the transected region + GDF5 application (500 ng) $24 \mathrm{~h}$ after partial transection; and with ADMSC and GDF-5 (ASC+GDF5): Rats with transected tendons and treated with subsequent transplant of ADMSC $\left(3.7 \times 10^{5}\right.$ cells) in the transected region + GDF5 application (500 ng) $24 \mathrm{~h}$ after partial transection. Animals were euthanized on the 14th day after transection by an overdose of anesthetic (Ketamine and Xylazine). Animals of group $\mathrm{N}$ were euthanized at 134 days and the tendons without transection were collected for analysis.

\subsubsection{Partial Transection of the Calcaneal Tendon and Application of ADMSC and GDF-5}

The animals were anesthetized with intraperitoneal injection of Ketamine $(90 \mathrm{mg} / \mathrm{Kg})$ and Xylazine $(12 \mathrm{mg} / \mathrm{Kg})$, and the right lower paws submitted to antisepsis and trichotomy. For the exposure of the calcaneus tendon, a longitudinal incision was made in the animal's skin, followed by a transverse partial transection performed in the proximal tendon region located at a distance of $4 \mathrm{~mm}$ from its insertion in the calcaneus bone [36,37]. Approximately $3.7 \times 10^{5}$ ADMSC (5P) were resuspended in $15 \mu \mathrm{L}$ of DMPBS Flush and transplanted in the transected region of tendons in the ASC group using a pipette. $15 \mu \mathrm{L}$ of DMPBS Flush was applied in tendons of the T group, and the GDF5 group tendons received an application of $15 \mu \mathrm{L}$ of DMPBS Flush $+500 \mathrm{ng}$ of GDF-5 $24 \mathrm{~h}$ after the tendon transection. All applications were made in the region of the tendon where the partial transection was performed. Then, the skin was sutured with nylon thread (Shalon 5-0) and a needle $(1.5 \mathrm{~cm})$. All surgical and experimental protocols were approved by the Institutional Committee for Ethics in Animal Research of the State University of Campinas-UNICAMP-Brazil (Protocol n ${ }^{\circ} 2905-1$ ).

\subsubsection{Preparation of Sections in Freezing}

Tendons were placed in Tissue-Tek ${ }^{\circledR}$, frozen, and cut in cryostat (serial longitudinal cuts of $7 \mu \mathrm{m}$ thickness). The sections were fixed using a $4 \%$ formaldehyde solution in Millonig buffer $(0.13 \mathrm{M}$ sodium phosphate and $0.1 \mathrm{M}$ sodium hydroxide, $\mathrm{pH}$ 7.4) for $20 \mathrm{~min}$, followed by birefringence and linear dichroism analysis. 


\subsubsection{DAPI Staining}

Immediately after fixation, the sections $(n=4)$ were incubated with DAPI (4',6-Diamidino-2-phenylindole dihydrochloride) $\left(0.1 \mathrm{mg} / \mathrm{mL}\right.$ in methanol) for $5 \mathrm{~min}$ at $37{ }^{\circ} \mathrm{C}$. The sections were analyzed by fluorescence microscope (Olympus BX60) and the images captured by the QCapture 4.0 program.

\subsubsection{Polarization Microscopy: Birefringence Measurements}

After fixation, image analyses of the tendons $(n=4)$ were evaluated to detect differences in morphology based on the aggregation and organization of the collagen bundles, which reflect the variation of birefringence intensity. Birefringence properties were studied using an Olympus BX53 polarizing microscope and an image analyzer (Life Science Imaging Software, Version 510_UMA_cellSens16_Han_en_00). Because the birefringence appears visually as brilliance, this phenomenon was measured with an image analyzer and expressed as gray average (GA) values in pixels ( 8 bits $=1$ pixel). The larger tendon axis was positioned at $45^{\circ}$ to the crossed analyzer and polarizer. As collagen bundles exhibit two types of birefringence, intrinsic birefringence (Bi) and form or textural birefringence (Bf) [38], the total birefringence (the sum of Bi and Bf) was used in this study. Measurements of the tendons in each experimental group were made after immersing the sections in water, a condition in which total birefringence is highly detectable $[4,33,34,38]$. The number of measurements of GA was represented as the median and they were chosen at random in 16 sections from four tendons of each group.

\subsubsection{Linear Dichroism Measurements}

Linear dichroism measurements $(n=4)$ were obtained from toluidine blue-stained sections. Linear dichroism measurements have shown that GAG chains present in collagen fiber PGs are linearly distributed and predominantly parallel to the longest fiber axis $[3,39,40]$. In this case, linear dichroism is an extrinsic phenomenon, resulting from the arrangement of toluidine blue molecules that are electrostatically bound to the anionic link sites of the oriented substrate. The dichroic ratio $\left(D R=d / d_{\perp}\right)$ was determined by the toluidine blue absorbance in the parallel $(\mathrm{d})$ and perpendicular $\left(\mathrm{d}_{\perp}\right)$ positions of the tendon's longest axis, with regard to the polarized light plane (PLP) [39,40]. Linear dichroism was measured using an Olympus BX53 polarizing microscope (Objective: Olympus UPlanFL N 40×; Camera: Olympus Q-color 5; Polarizer: Olympus U-POT) and an image analyzer (Life Science Imaging Software, Version 510_UMA_-cellSens16_Han_en_00). The number of measurements ( 100) of GA was represented as the median and they were chosen at random in 16 sections from four tendons of each group.

\subsubsection{Real Time-PCR Array}

The collected tendons $(n=4)$ were placed in stabilizing solution (RNA-later, QIAGEN ${ }^{\circledR}$ Hilden, Germany) and maintained at $-20{ }^{\circ} \mathrm{C}$. For the total RNA extraction, the tendons were sprayed using liquid nitrogen and then homogenized in a tube containing 5 stainless steel balls $(2.3 \mathrm{~mm}$ diameter, Biospec) by being shaken in a TissueLyser LT instrument (QIAGEN ${ }^{\circledR}$ Hilden, Germany), with 2 repetitions (60 s) intercaleted with ice cooling ( $2 \mathrm{~min}$ ) between each shaking step (5). Total RNA was isolated from each sample using the RNeasy ${ }^{\circledR}$ Fibrous Tissue Mini Kit (QIAGEN ${ }^{\circledR}$ Hilden, Germany), following the manufacturer's instructions. A spectrophotometer (NanoDrop ${ }^{\circledR}$ ND-1000, Thermo Fisher Scientific ${ }^{\circledR}$, Waltham, Massachusetts, USA) was used to quantify the RNA in each sample by determining the absorbance ratio at 260 and $280 \mathrm{~nm} .0 .5 \mu \mathrm{g}$ from the total extracted RNA of each sample was used for the synthesis of cDNA using the RT $^{2}$ First Strand Kit (QIAGEN ${ }^{\circledR}$ Hilden, Germany) and thermocycler Mastercycler Pro (Eppendorf ${ }^{\circledR}$ Hamburg, Germany), also following the manufacturer's instructions. The cDNA was frozen at $-20{ }^{\circ} \mathrm{C}$ until tested. The RT-PCR array reaction was performed using the $\mathrm{RT}^{2}$ Profiler PCR Arrays (A format) kit in combination with the $\mathrm{RT}^{2} \mathrm{SYBR}$ 
Green Mastermixes (QIAGEN ${ }^{\circledR}$ Hilden, Germany) on the thermocycler apparatus 7300 (ABI Applied Biosystems ${ }^{\circledR}$, Foster City, CA, USA), following the manufacturer's instructions. For each animal sample, three types of reaction controls were used: 1 . Positive PCR control; 2. Reverse transcriptase control; and 3. Control for contamination of rat genomic DNA. The Glyceraldehyde-3-phosphate dehydrogenase (Gapdh, NM_017008) was used as an endogenous control for each sample. The following genes were analyzed (QIAGEN ${ }^{\circledR}$ Hilden, Germany): Scleraxis (Scx, NM_001130508); Tenomodulin (Tnmd, NM_022290); Tumor necrosis factor (TNF superfamily, member 2) (Tnf, NM_012675); Interleukin 1 beta (II1b, NM_031512); Transforming growth factor, beta 1 (Tgfb1, NM_021578); Matrix metallopeptidase 2 (Mmp2, NM_031054); Matrix metallopeptidase 9 (Mmp9, NM_031055); Matrix metallopeptidase 8 (Mmp8, NM_022221); TIMP metallopeptidase inhibitor 2 (Timp2, NM_021989); Decorin (Dcn, NM_024129); Lysyl oxidase (Lox, NM_017061); and Growth differentiation factor 5 (Gdf5, XM_001066344). Reactions were made in a single cDNA pipette for each gene, including the endogenous control. $\triangle \mathrm{CT}$ values were obtained by the difference between the CT values of the target genes and the Gapdh gene. These values were normalized by subtracting the $\Delta \mathrm{CT}$ value of the calibrator sample (T group) to obtain $\Delta \Delta \mathrm{CT}$ values. A $2^{-\Delta \Delta C T}$ method was used to calculate the relative expression level (fold change) for each target gene. Results were represented as the relative gene expression in comparison to the calibrator sample that is equal to 1 .

\subsubsection{Dosage of Hydroxyproline}

Hydroxyproline was used as an indicator of the amount of total collagen in the tendons of the different groups $(n=5)$ used previously in the biomechanical assay. The tendons were cut and immersed in acetone for $48 \mathrm{~h}$, followed by a solution containing chloroform:ethanol (2:1) also for $48 \mathrm{~h}$. After dehydration, the samples were placed for drying in the oven at $37^{\circ} \mathrm{C}$. Samples were weighed and hydrolyzed in $6 \mathrm{~N} \mathrm{HCl}\left(1 \mathrm{~mL} / 10 \mathrm{mg}\right.$ of tissue) for $4 \mathrm{~h}$ at $130{ }^{\circ} \mathrm{C}$ according to Stegemann and Stalder [41] with some modifications, and neutralized with $6 \mathrm{~N} \mathrm{NaOH}$. The absorbance of the samples was measured at $550 \mathrm{~nm}$ using a microplate reader (Expert Plus, Asys ${ }^{\circledR}$, Holliston, MA, USA).

\subsubsection{Evaluation of the Max Contact Intensity of the Rat Paw after Partial Transection}

The CatWalk system (Noldus Inc., Wageningen, The Netherlands) was used to analyze the gait recovery of the animals $(n=5)$. In this protocol, the rats crossed a walkway $(100 \mathrm{~cm}$ length, $5 \mathrm{~cm}$ width, and $0.6 \mathrm{~cm}$ thickness) with a glass floor illuminated from the long edge in a dark room. Data acquisition was performed with a high-speed camera (Pulnix TM-765E CCD), and the paw prints were automatically classified by the software. The paw prints were obtained during the 3 days before the partial transection of the tendons to assess the normal standard gait of the animals, and they were collected again after the lesions. Post-operative data were assessed on the 1st, 3rd, 5th, 7th, 9th, 11th, and 13th days following surgical lesion. The parameters used herein were "Max Contact Intensity", corresponding to the pressure exerted by the paw on the glass floor during gait. The intensity of magnification can vary from 0 to 255 pixels.

\subsubsection{Biomechanical Parameters}

Tendons from experimental groups $(n=5)$ were collected and stored at $-20{ }^{\circ} \mathrm{C}$ until tested. Before the biomechanical test, the tendons were thawed and measured with pachymeter, considering their length, width, and thickness. For the biomechanical assay, the tendons were maintained in PBS to prevent their fibers from drying out. Then, the tendons were fixed to metal claws by the myotendinous junction and by the osteotendinous junction for correct alignment in the equipment (Texturometer, MTS model TESTSTAR II). In each biomechanical assay, tendons were subjected to a gradual increase of load at a displacement velocity of $1 \mathrm{~mm} / \mathrm{s}$ by using a load $0.05 \mathrm{~N}$ until the tendon ruptured. Biomechanical parameters were analyzed according to Biancalana et al. [42] and Tomiosso et al. [9], such as maximum force $(\mathrm{N})$ and maximum displacement $(\mathrm{mm})$, which were used to calculate the maximum stress (Mpa) and maximum strain $(\mathrm{L})$ of tendons from the experimental 
groups. The cross-sectional area of the calcaneus tendon was calculated by assuming an elliptical approximation $(\mathrm{A}=\pi \mathrm{Wd} / 4)$ using measurements of width $(\mathrm{W})$ and thickness $(\mathrm{d})$ values from the same Sparrow et al. [43]. The maximum stress value (MPa) was estimated by the ratio between the maximum load $(\mathrm{N})$ and the cross-sectional area $\left(\mathrm{mm}^{2}\right)$. The maximum deformation $(\mathrm{L})$ was calculated through $\left(\mathrm{L}=\mathrm{L}_{\mathrm{f}}-\mathrm{L}_{\mathrm{i}} / \mathrm{L}_{\mathrm{i}}\right)$, where $\left(\mathrm{L}_{\mathrm{f}}\right)$ is the value of the final length before rupture, and $\left(\mathrm{L}_{\mathrm{i}}\right)$ is the initial tendon length value. Stress-strain curves were constructed using the mean of each mechanical property obtained for each group.

\subsubsection{Statistical Analysis}

All results were presented as the mean and standard deviation for the values with a normal distribution (or interquartile range and median for the values that did not adhere to the Gaussian distribution). For the data with normal distribution, the analysis of variance (ANOVA) was used, followed by the Tukey post-hoc test for intra-group analysis (in the case of statistical significance), or the Student's $t$ Test preceded by the Levene Test. For data that did not adhere to the Gaussian distribution, the non-parametric test of the Kruskal-Wallis test followed by the post-hoc test of Dunn for intra-group analysis (in the case of statistical significance) was used or the U Test of Mann-Whitney. Statistical analysis was performed in the software Statistical Package for Social Sciences (SPSS) version 22.0 and for all the aforementioned tests the significance level $\alpha=0.05$ and power of the test of $95 \%$ were considered.

\section{Results}

\subsection{In Vitro}

\subsubsection{In Vitro Differentiation Potential of ADMSC and Flow Cytometry}

In vitro ADMSC staining with Toluidine Blue, Alizarin Red S, and Sudan IV showed differentiation of ADMSC at the 5P in chondrocytes, osteoblasts, and adipocytes, respectively (Figure 1A-C). Flow cytometric analysis (Figure 1D,E) showed the presence of CD90 (90\%) and CD105 (95\%) positive surface markers, and the negative marker, CD45 (75\%).
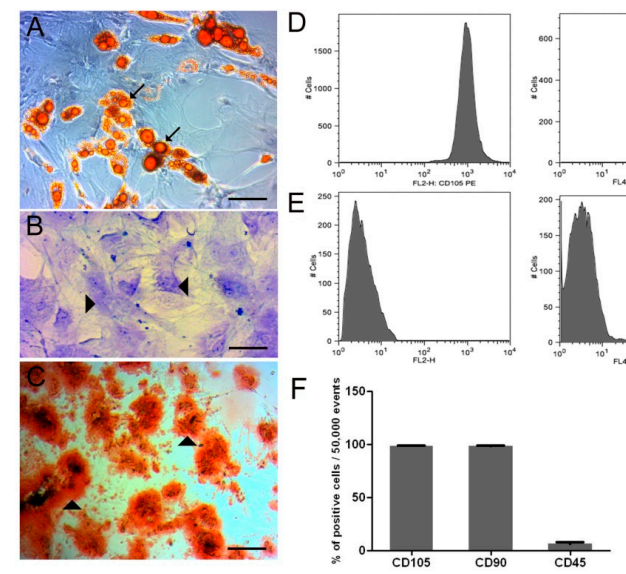

Figure 1. In vitro adipogenic (A), condrogenic (B), and osteogenic (C) differentiation of adipose-derived mesenchymal stem cells (ADMSC) in 5P: Observe intracellular lipid droplets stained with Sudan IV $(\rightarrow)$, proteoglycans stained with toluidine blue $(\nabla)$, and extracellular calcium stained with alizarin red S ( ). Bars = A and C: $200 \mu \mathrm{m}$; B: $100 \mu \mathrm{m}$. (D) Histograms demonstrate the x-axis fluorescence scale considered positive when the cell peak is above $10^{1}$ (CD45) or $10^{2}$ (CD105 and CD90). (E) Control for -PE and -APC (with very low fluorescence), corresponding to non-marked cells. (F) Flow cytometry of ADMSC for CD105, CD90, and CD45 surface markers. 


\subsubsection{Fluorescence, Birefringence, and Contrast by Differential Interference (DIC)}

Analysis using fluorescence microscopy showed ADMSC-GFP on 5P with fusiform fibroblast-like morphology (Figure 2A). When DIC was used, nucleoli were observed (Figure 2B). On AT (pH 4.3) staining, most of the nuclei were stained in blue, with the presence of granules of various sizes in some regions being highly stained in blue (Figure 2C). Under polarizing microscopy, the granules exhibited abnormal interference colors due to differences in the high packing of DNA (Figure 2D).

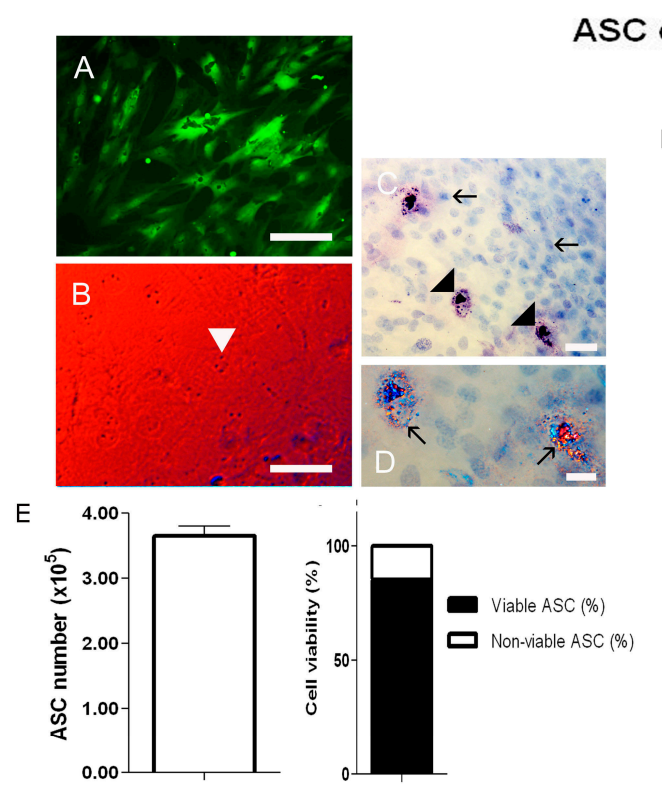

ASC on 5P

$\mathrm{F}$

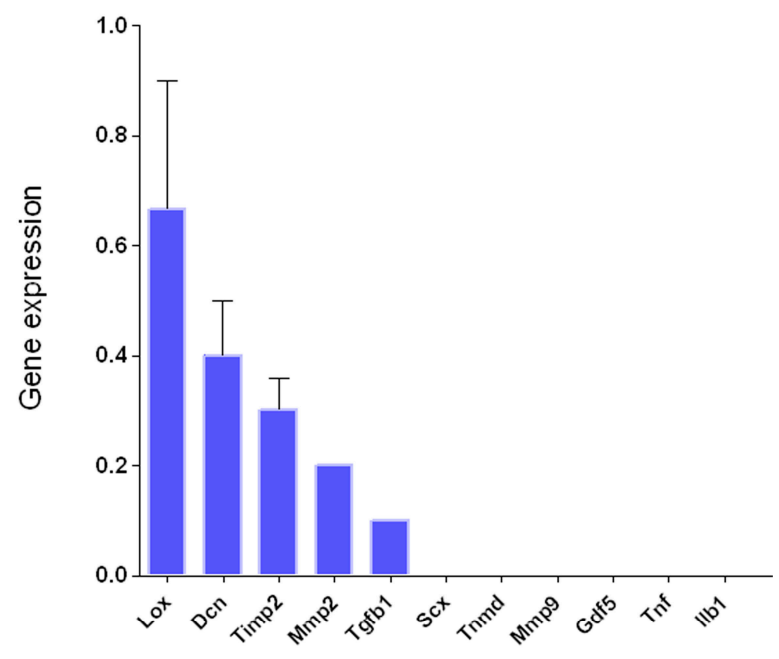

Figure 2. Morphology of ADMSC on 5P: (A) ADMSC-GFP: Fibroblast-like morphology, with a fusiform shape. (B) Contrast by Differential Interference (DIC): The red to blue band showing the interference effect of the nucleus due to higher concentrations of material. Nucleoli presence seen in the initial of the blue band $(\bullet)$. (C) ADMSC stained with AT (pH 4.3): Note the presence of nuclei stained in blue $(\rightarrow)$, and the presence of granules of various sizes highly stained in blue in some regions $(\downarrow)$ due to the disponibility of phosphate groups. (D) Polarization microscopy: In the detailed image, note the abnormal interference colors due to abnormal dispersion of birefringence because of the differences in the high packing of DNA. Bars $=50 \mu \mathrm{m}(\mathbf{A}), 70 \mu \mathrm{m}(\mathbf{B}, \mathbf{C})$, and $35 \mu \mathrm{m}(\mathbf{D})$. (E) Number of ADMSC used for application in tendons, presenting about $80 \%$ viability after tripsinization. (F) RT-PCR array of ADMSC on 5P in vitro showing the expression profile of the genes Lox, Dcn, Timp2, Mmp2, and Tgfb1. No expression was observed for Scx, Tnmd, Mmp9, Gdf5, Tnf, and Ilb1 genes.

\subsubsection{Cell Viability}

Figure 1E showed a mean of $3.7 \times 10^{5}$ ADMSC used for tendons' application of the ADMSC and ASC+GDF5 groups, with a mean of $80 \%$ of viable ADMSC (Figure 2E).

\subsubsection{Real-Time PCR Array}

In the RT-PCR array analysis of ADMSC on 5P, the expression profile of the genes, Lox, Dcn, Timp2, Mmp2, and Tgfb1 was observed. No expression was observed for the Scx, Tnmd, Mmp9, Gdf5, Tnf, and Ilb1 genes. The expression of the Mmp8 gene was not represented because only one culture expressed it (Figure 2F). 


\subsection{In Vivo}

\subsubsection{Immunofluorescence}

In the present study, significant alterations in the ECM of the Achilles tendon were observed after 14 days since the partial transection, both from the application of the ADMSC isolated in the injured region and from the application of the ADMSC associated with GDF-5. The cell migration assay demonstrated the presence of ADMSC-GFP in tendon sections of both groups, ASC and ASC+GDF5, on the 3rd and 14th days after injury (Figure 3).

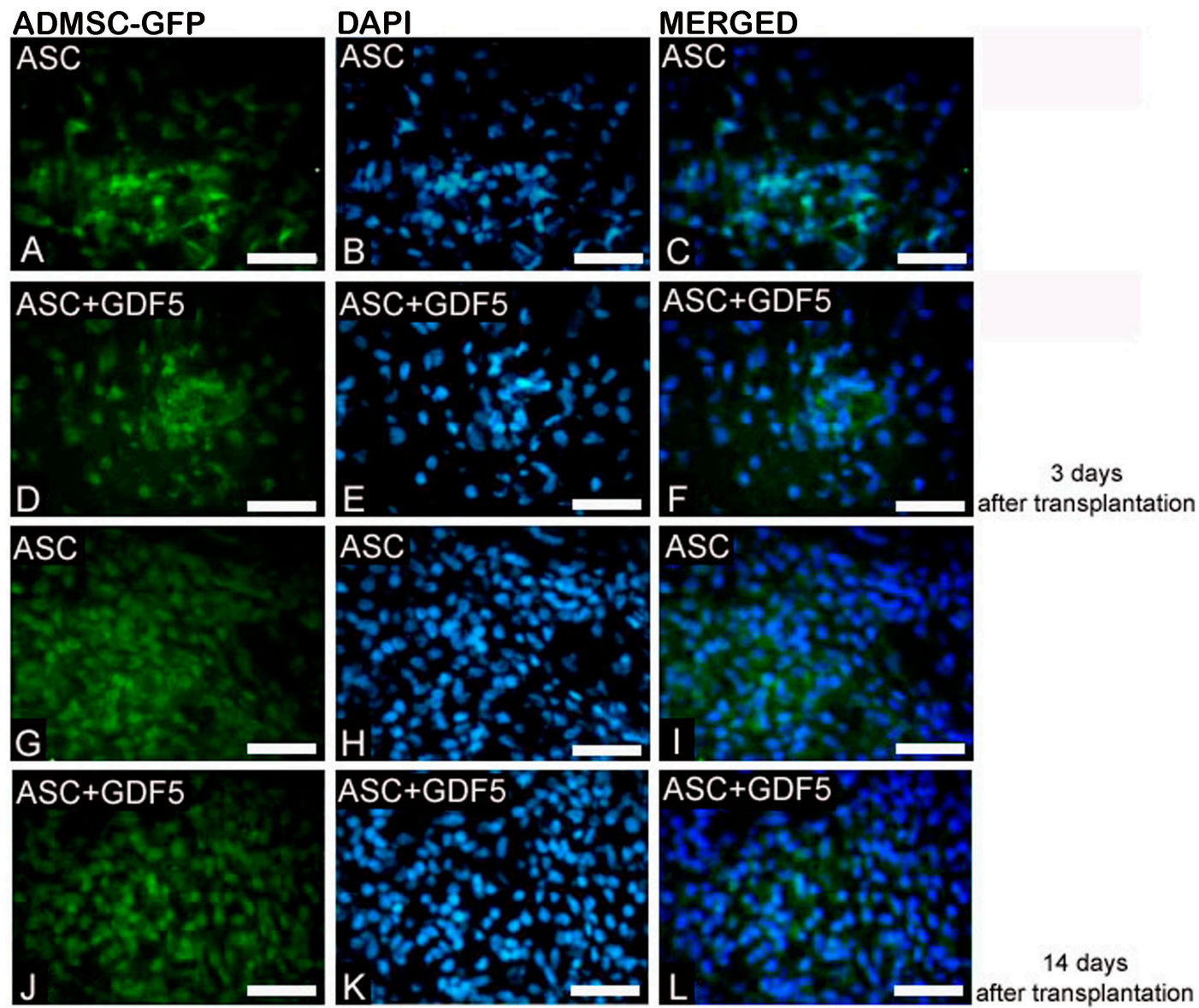

Figure 3. ADMSC-GFP Migration to TR on the 3rd and 14th days after injury: Observe the presence of ADMSC-GFP $(\mathbf{A}, \mathbf{D}, \mathbf{G}, \mathbf{J})$ in the ASC and ASC+GDF5 groups. Visible higher numbers of cells can be observed on the 14th day in both groups. DAPI: Nuclei marking $(\mathbf{B}, \mathbf{E}, \mathbf{H}, \mathbf{K})$. Merged images of ADMSC-GFP with nuclei marked with DAPI (C,F,I,L). Bar $=50 \mu \mathrm{m}$.

\subsubsection{Real-Time PCR Array}

The 12 genes expression analysis, obtained through the RT-PCR array (Figure 4), showed that the ADMSC application up-regulated the expression of the $L o x, D c n$, and $T g f b 1$ genes compared to the T group, and of the Mmp2, Timp2, and Gdf5 genes in relation to the ASC+GDF5 group. 

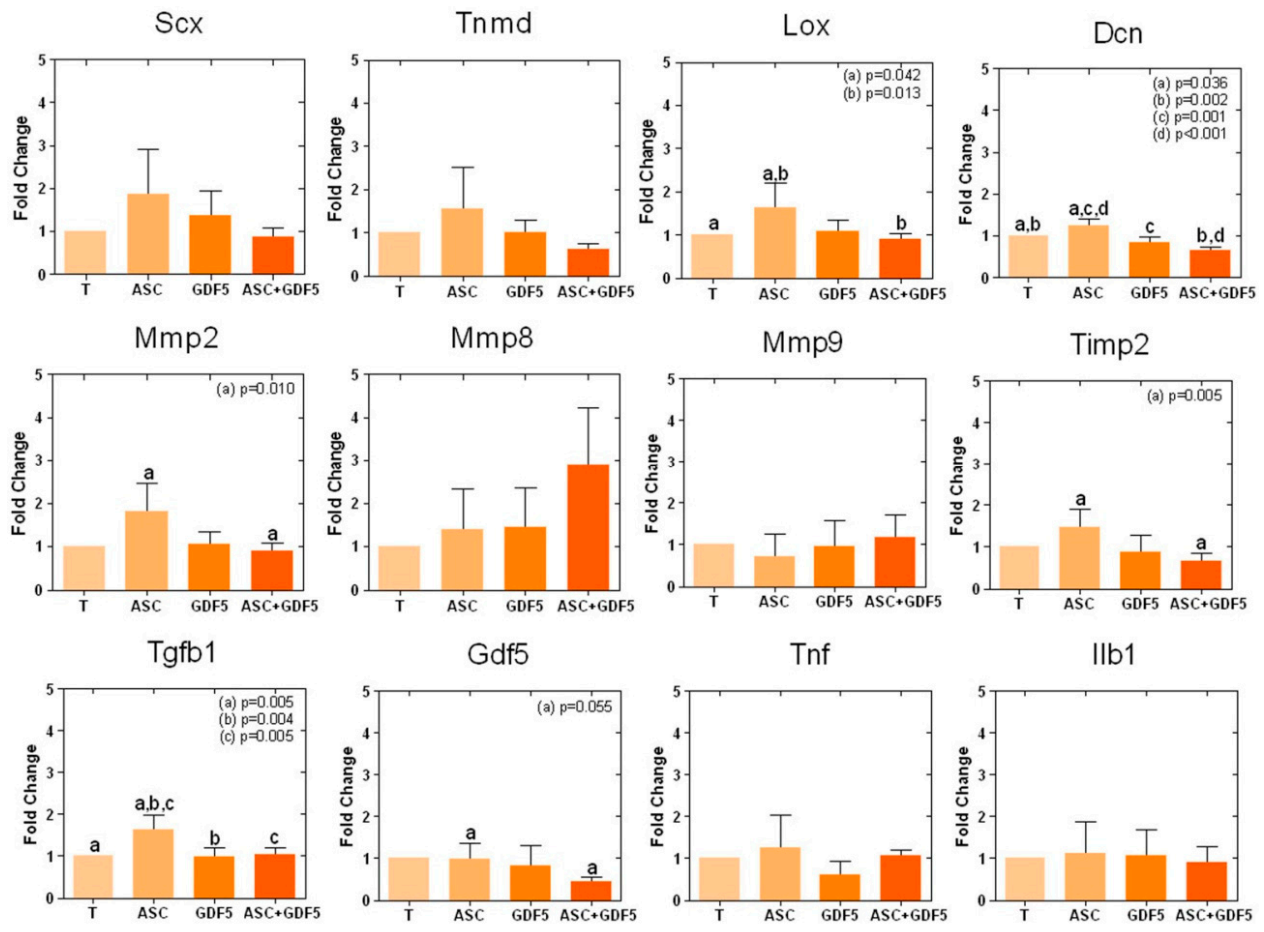

Figure 4. RT-PCR array for expression analysis of 12 genes in transected tendons: $50 \%$ of the genes analyzed were altered. The ADMSC increased expression of $L o x, D c n$, and $T g f b 1$ when compared to the other groups. Compared only to the ASC+GDF5 group, ADMSC increased the expression of Mmp2, Timp2, and Gdf5. The same letter between the groups corresponds to a significant difference between them.

\subsubsection{Dosage of Hydroxyproline}

Regarding the hydroxyproline dosage (Figure 5), which infers the concentration of total tissue collagen (mg/g of tissue), a lower value was demonstrated in the ASC+GDF5 group in relation to all other groups.

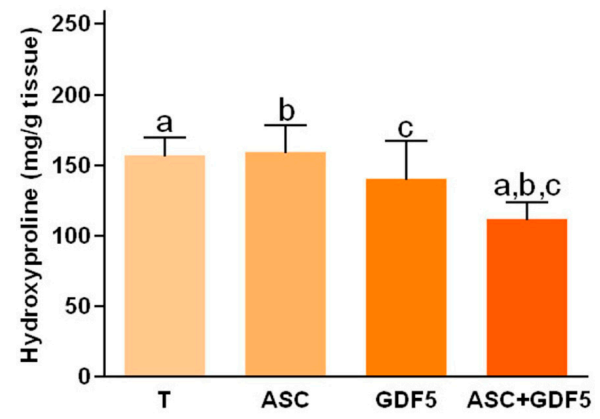

Figure 5. Tendons hydroxyproline concentration: Observe the lower value in the ASC+GDF5 group in relation to the other groups. The same letter among groups corresponds to a significant difference between them $(p \leq 0.05)$.

\subsubsection{Birefringence Measurements}

In the birefringence measurements obtained through polarization microscopy (Figure 6), differences were observed in the collagen fiber organization of the tendons of the different groups. The tendons analyzed areas were characterized as follows: Transection region (TR), where partial transection of the collagen bundles was performed; and proximal and distal transition region 
(T1), which are located in the adjacency of the TR. Considering the TR, the T group presented higher birefringence values (gray average values in pixels) in relation to the other transected groups. The ASC group, in relation to the groups, GDF5 and ASC+GDF5, had a higher value of birefringence. Regarding the organization of the collagen bundles in T1, the ASC group presented greater birefringence in relation to the other groups, and GDF5 presented a lower value also in relation to the T group. Regarding the organization pattern of the crimp, no significant difference was observed between groups.
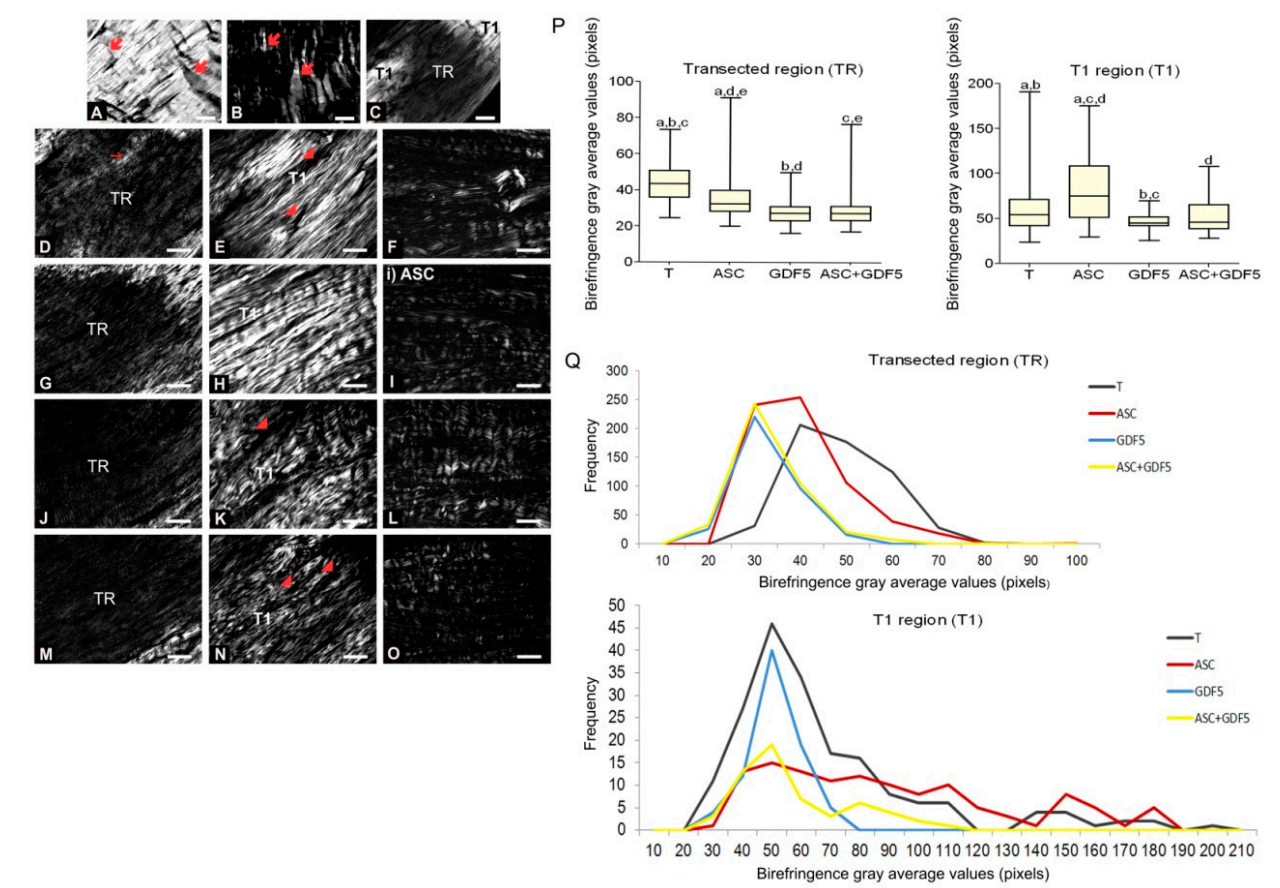

Figure 6. Images of tendons using polarization microscopy. (A) group N: Birefringence of the collagen fibers in the proximal region of the calanear tendon. The variation in gray levels is due to the crimp and the degree of aggregation of the collagen fibers $(\boldsymbol{K})$; observe the crimp (B) by positioning the largest axis of the tendon parallel to one of the polarizers: The same region observed in (A). (C) Panoramic image of the transected tendon for identification of the transection region (TR) and the proximal and distal transition region (T1). Groups T (D-F), ASC (G-I), GDF5 (J-L), and ASC+GDF5 (M-O). Observe the complete disorganization of collagen fibers in TR. The TR from different groups $(\mathbf{D}, \mathbf{G}, \mathbf{J}, \mathbf{M})$ : Observe freshly formed collagen fibrils and an overlapping $(\searrow$ ) of this region with the thicker fibers present in T1. $\mathbf{T 1}(\mathbf{E}, \mathbf{H}, \mathbf{K}, \mathbf{N})$ : Collagen fibers with a greater organization in relation to TR, however, with fragmentation presence ( $\boldsymbol{\Lambda}$ ) mainly in groups T (E), GDF5 (K), and ASC+GDF5 (N). Crimp $(\mathbf{F}, \mathbf{I}, \mathbf{L}, \mathbf{O})$ from the collagen fibers observed on T1: Observe similar undulation patterns of the collagen fibers between the groups, represented by light and dark regions. The largest axis of the tendon was positioned at $45^{\circ}$ in relation to the crossed polarizers as parallel to one of the polarizers $(\mathbf{B}, \mathbf{F}, \mathbf{I}, \mathbf{L}, \mathbf{O})$. (P) TR birefringence measurements in T1: Same letter represents significant differences between groups $(p \leq 0.05)$. (Q) Histogram of the frequency and birefringence values showing differences in the distribution of values in the different groups. Bars $=100 \mu \mathrm{m}$ and $200 \mu \mathrm{m}$ (a).

\subsubsection{Linear Dichroism Measurements}

The dichroic ratio (DR) calculated from the linear dichroism measurements performed in sections stained with toluidine blue (Figure 7), through the use of polarization microscopy, showed differences in the organization of the PG present in the TR of the tendons. The T group presented higher DR when compared to the ASC and ASC+GDF5 groups, followed by the GDF5 group, with a higher value in relation to the ASC group. 


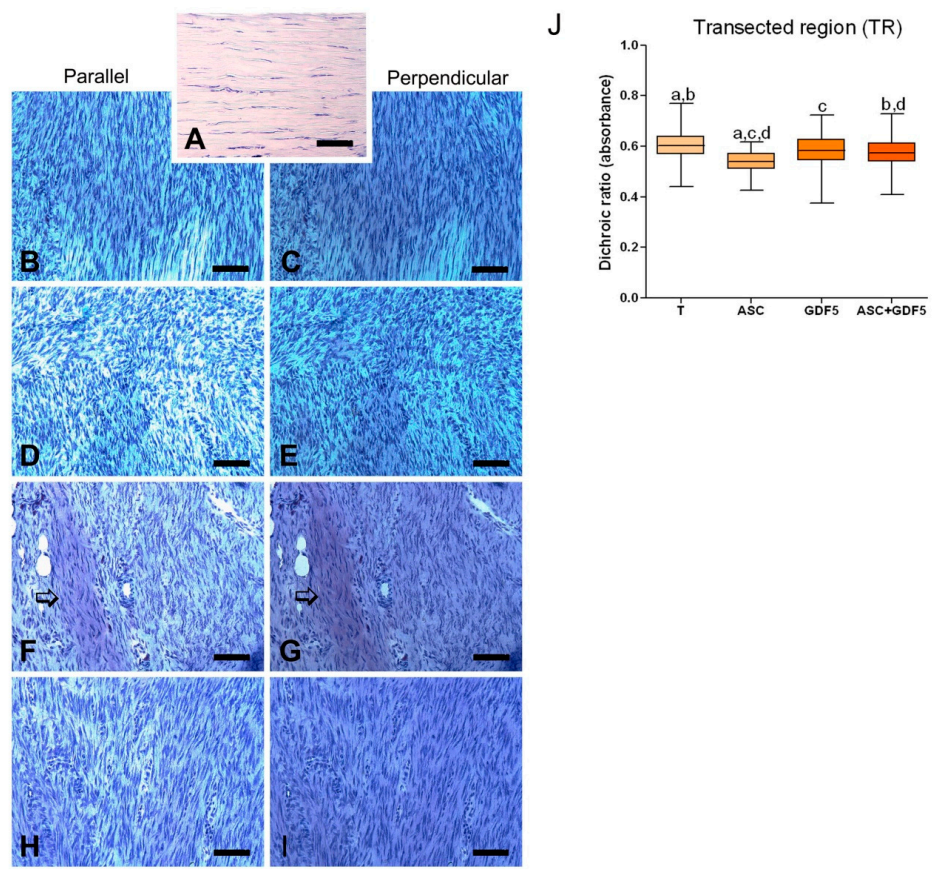

Figure 7. Linear dichroism (DL) of AT-stained tendon sections and analyzed under polarization microscopy. The largest axis of the tendon was placed in the parallel $(\mathbf{B}, \mathbf{D}, \mathbf{F}, \mathbf{H})$ and perpendicular $(\mathbf{C}, \mathbf{E}, \mathbf{G}, \mathbf{I})$ position relative to the polarized light plane. Observed DL is typically more intense in the cuts in the perpendicular position. Group N (A) is observed under common light microscopy due to the low amount of PG. (J) Dichroic index (ID) calculated through linear dichroism measurements (absorbance) performed on tendons TR: Greatest value observed in group T. Same letter between groups corresponds to a significant difference between them $(p \leq 0.05)$. Bar $=100 \mu \mathrm{m}$.

\subsubsection{CatWalk System}

In the functional analysis obtained through CatWalk (Figure 8), differences were observed in the rats' gait in the different groups. Considering the maximum contact intensity of the paw (pixels) during gait, the ASC+GDF5 group presented a higher value in relation to the T and GDF5 groups $24 \mathrm{~h}$ after the transection. Between the 5th and 13th days after transection, the ASC group presented higher values in relation to the GDF-5 treated groups, although without a significant difference in relation to the T group.

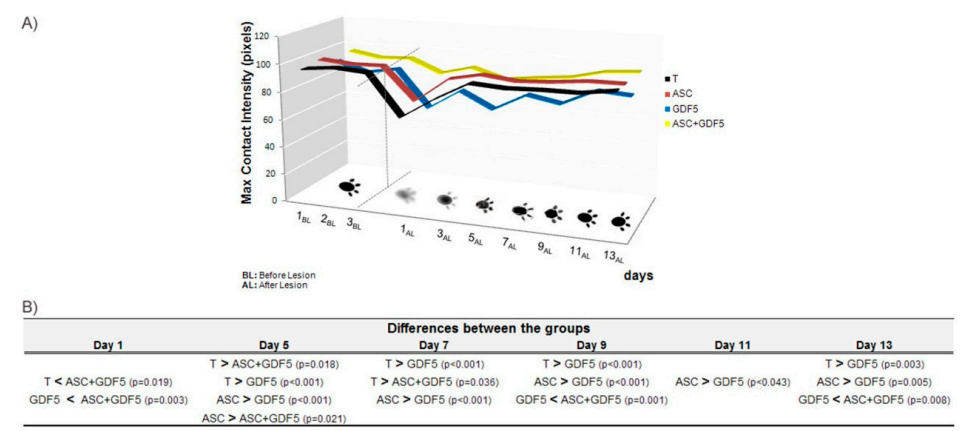

Figure 8. (A) Maximum contact intensity of the paw of the animals during walking, obtained through the CatWalk system. The measurements were taken three days before the injury to obtain the normal walk pattern, and on the 1st, 3rd, 5th, 7th, 9th, 11th, and 13th days after the tendon transection. Observe the marked decrease in contact pressure of the animals' paw on the day after surgery, with a higher value of the ASC+GDF5 group compared to the T group. Except for the GDF5 group, observe the complete recovery of the normal walk pattern of the animals in the other groups on the 13th day. (B) Comparisons between groups with significant differences observed between the 1st and 13th days. 


\subsubsection{Biomechanical Parameters}

The biomechanical analyses of the Achilles tendon (Figure 9A) showed significant differences between the groups considering some parameters. Regarding the maximum rupture load, the ASC group presented a higher value in relation to the GDF5 and ASC+GDF5 groups. Considering the displacement and strain parameters, the groups treated with GDF-5 presented higher values in relation to the T and ASC groups. No difference was observed in the cross-sectional area between the groups. In the stress-strain curve (Figure 9B), tendons treated with ADMSC presented lower deformation at higher stress in comparison to the other groups.
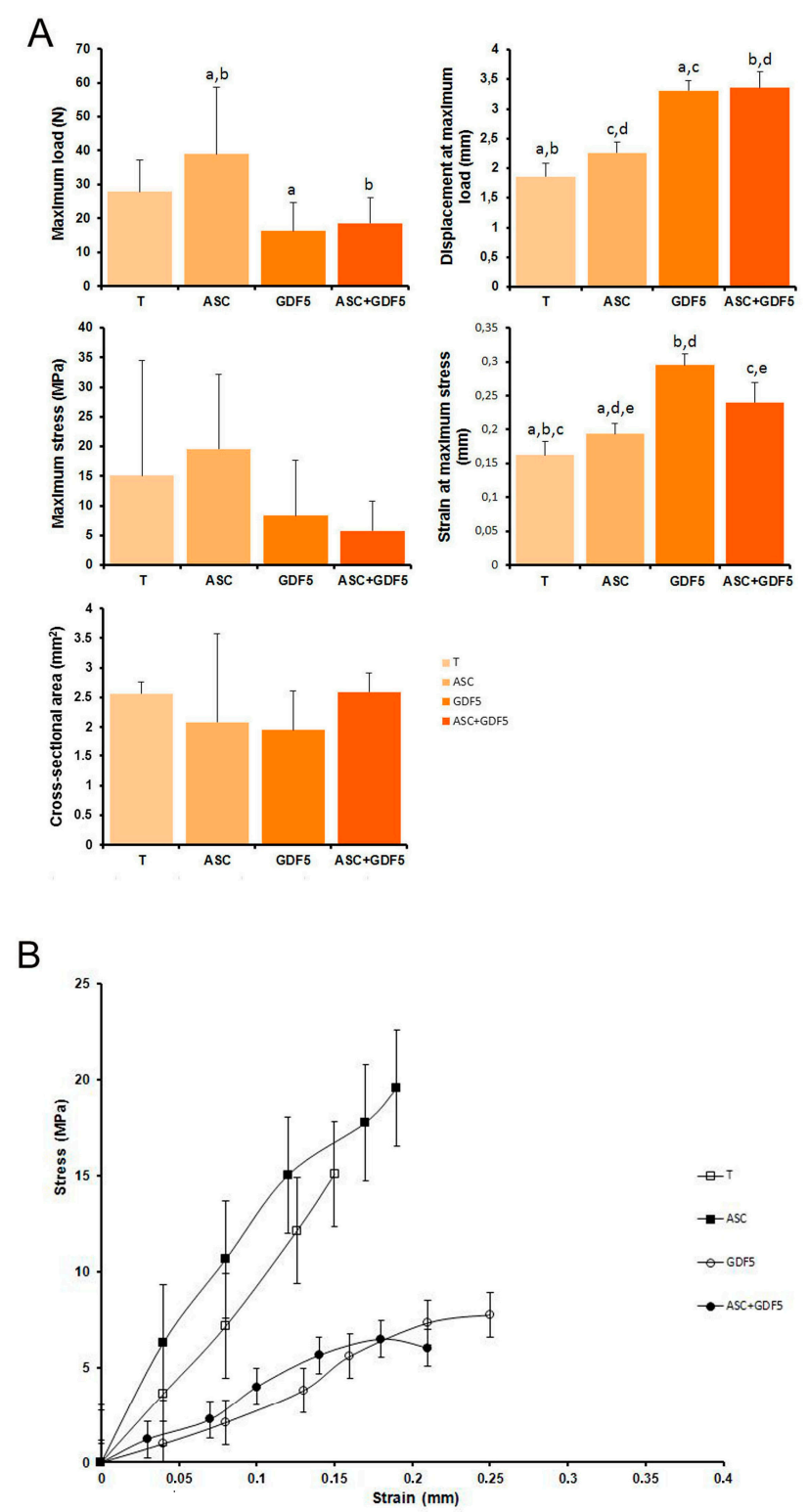

Figure 9. (A) Biomechanical properties of the tendons: Significant differences can be observed between the groups for the parameters of maximum load, displacement, and strain. The same letter between the groups corresponds to a significant difference between them $(p \leq 0.001)$. (B) Stress-strain curve: Tendons treated with ADMSC presented lower deformation at higher stress in comparison to the other groups. Standard deviations are represented by vertical bars. 


\section{Discussion}

Several current therapeutic techniques have been applied with the objective of improving tendon healing with partially satisfactory results considering its functional repair. The healed tendon is often characterized by functional impairment and a risk of re-rupture, mainly at the site of injury or near the injury region [13]. Recently, ADMSC have been proposed as a new treatment to improve this repair process due to its multipotency, cultivation facility, high yield, and, because they originate from adult donors, lack of ethical issues. In the present study, in the characterization of the cells before application, ADMSC expressed the positive surface markers, CD90 and CD105, and low expression of the negative marker, CD45. ADMSC also differentiated in chondrocytes, osteoblasts, and adipocytes, showing multilineage differentiation. Nucleoli were also observed in the ADMSC, indicating their synthesis activity, as an interesting profile of genes expression was exhibited by the ADMSC in vitro due to the expression of Lox, Dcn, Mmp2, Timp2, and Tgfb1 genes, and no expression of the genes, $S c x$, Tnmd, Mmp9, Gdf5, Tnf, and Ilb1.

The transplanted ADMSC-GFP migrated to the transected tendon region in response to the specific microenvironment of the injury, characterized by the intense initial inflammatory process [44,45], and remained until the 14th day of the repair process. Thus, the alterations found in the groups after ADMSC transplantation are directly associated with the incorporation of these cells into the tendon. It is important to mention that at the time of tendons application, a mean of $80 \%$ of viable ADMSC were transplanted. According to Gimble et al. [18], the use of ADMSC is promising in several repair processes because of their potential for differentiation in different cell lines, as well as the secretion of growth factors and other signaling molecules.

In the present study, ADMSC increased the organization of collagen fibers in the injury adjacent region, which was reflected in the biomechanical properties of the tendons. Compared to the control transected tendon, tendons treated with ADMSC were apparently more resistance to traction, with lower deformation at higher stress. The organization and mechanical properties of the tendon are determined mainly by the orientation of fibrils and collagen fibers, fiber diameter, number of intra- and inter-molecular crosslinks that guarantee high tensile strength, total collagen content, the amount of PG, and the presence of other non-collagen proteins, such as cytokines, growth factors, and structural proteins $[8,9,46-48]$. Some studies have shown the effectiveness of ADMSC in some models of tendon injury. Results from Del Bue et al. [49] showed the benefits of ADMSC application, in association with a platelet concentrate, in the functional recovery of horses' tendons. In a model of rabbits' calcaneal tendon injuries, the application of ADMSC associated with a gel composed of a plasma rich in platelets increased the biomechanical resistance of the tendons in the 4th week of the healing process and increased the amount of collagen type I, VEGF, and FGF [7]. Uysal and Mizuno [50] also showed the effectiveness of the application of ADMSC in isolation at the site of the tendon injury, in which there was an increase in tendon resistance to tension, increase of angiogenic growth factors, and differentiation of stem cells into tenocytes and endothelial cells.

The application of ADMSC in association to GDF-5 led to a lower concentration of total collagen and a low degree of organization of ECM tendon, evidenced by the low birefringence of the collagen fibers when compared to the group that received only the ADMSC. Our results indicate that the application of GDF-5 alone and when associated with ADMSC both reduce tissue organization, resulting in inferior biomechanical properties when compared to control transected tendons, as well as in relation to the tendons transected and the ADMSC treated ones. However, several studies have demonstrated the modulatory action of GDF- 5 on the tendon healing process due to its effect on cell migration and adhesion, differentiation, proliferation, and angiogenesis [28,29,31,51].

The beneficial role of GDF- 5 was also demonstrated in the study by Mikic et al. [52] using deficient GDF- 5 mutant mice, in which the tendons of these animals showed $40 \%$ less collagen compared to control tendons, as well as biomechanically less resistant tendons. A study by Chhabra et al. [31] reported that deficient GDF-5 mice presented until the 8th week of the healing process of the calcaneal tendon, a delay of one to two weeks in this process, characterized by a lower collagen concentration 
and smaller fibrils diameter collagen, lower amount of glycosaminoglycans (GAG), lower cell and blood vessel density, greater amount of fat, and lower biomechanical resistance until the 12th week. Rickert et al. [53] used gene therapy for the endogenous production of GDF-5 by genetically modified cells, which were applied to the injured tendon. Although the tissue quality was slightly greater than the control tendon, the presence of cartilaginous tissue was observed in the 8th week, disappearing in the 12th week of the healing process. Thus, it is possible to conclude that the lower biomechanical properties observed in the GDF-5 treated groups are directly related to the smaller organization of the fibers [48], as well as to the lowest total collagen content.

A lower dichroic ratio was observed in the ADMSC treated groups compared to the only transected group, indicating changes in the GAG arrangement in the collagen fibers present in the tendons of these groups. GAG chains are constituents of PG, which may be associated with collagen fibers through non-covalent interactions. Additionally, in normal tendons, the GAG chains present in PG are predominantly parallel to the major axis of the tendon [3]. A study by Mello and Vidal 40] showed differences in the arrangement of GAG up to 110 days after calcaneal tendon injury in rats. Thus, the lower dichroic ratio observed in the group treated with ADMSC alone suggests that not all GAG chains are neatly parallel to the major axis of the tendon, corroborating to the smaller organization of newly formed collagen fibers in the TR of the same group. The small PG play an important role in the fibrilogenesis of the collagen, regulating the growth in the fiber diameter [6]. It is important to emphasize that both groups treated with GDF-5 presented a higher dichroic ratio in relation to the ASC group, although less organization of the collagen fibers was observed in these groups treated with GDF-5.

Growth factors are small peptides, which generally transmit signals between cells, and are thus molecules that modulate cellular activity. In general, growth factors can regulate cell activity through several mechanisms, such as mitogenic activity, cell differentiation, cell migration, and gene regulation; and also play an important role in cellular chemotaxis and ECM synthesis [54,55]. The application of growth factors with the goal of improving the tendon healing process is still experimental, and has been restrictive to in vitro experiments and animal models $[55,56]$. The association of GDF-5 to the ADMSC used in this study was mainly based on the in vitro results of Park et al. [19]. An increase in ADMSC proliferation after GDF-5 application, and an increase in the amount of type I collagen, decorin, and aggrecan was seen, as well as markers of tendon cells, such as Scx, Tnmd, and tenascin-C, which have indicated differentiation of ADMSC in tenocytes [19]. However, in vivo, our results demonstrated low effectiveness of both the application of GDF- 5 alone and after its application in association with ADMSC.

The literature points to a limitation in the application form and frequency of growth factors during tendon healing due to the relatively short half-life of these factors, which would only allow the short-term modulation of their biological effects [53]. Results from Forslund et al. [30] showed interesting data after a single injection (six h after the tendon injury) of different doses $(0.4,2$, and $10 \mu \mathrm{g})$ of GDF-5, -6 , and -7 . On the 8th day after surgery, all factors increased the biomechanical resistance of the rats' calcaneal tendon after the application of the higher doses of 2 and $10 \mu \mathrm{g}$, in addition to observing a decrease in the inflammatory process. Yet, after the application of $10 \mu \mathrm{g}$ of the factors in this same study, bone and cartilaginous formation in the tendons was observed. In the present study, $500 \mathrm{ng}$ of GDF-5 was used based on the data of Park et al. [19] that treated the culture of ADMSC with different concentrations of GDF-5 (0-1000 ng/mL).

The application of GDF-5 in this study occurred 24 hours after tendon transection. Considering the important participation of the GDF- 5 in tendon repair, mentioned above in several studies, and as most of our results indicate a greater effectiveness of applying only ADMSC during this phase of the tendon repair process, important variables should be GDF-5: The animal model used, the model of tendon injury, including the extent of the injured area, the origin of the growth factor, and the dosage and form of administration of the same, as well as the period elapsed between injury and the application of the growth factor [57]. According to some authors, the administration of the growth 
factor after one week of surgery results in an improvement in the quality of the healing process, including improvement in the biomechanical properties of the tendon and the structural organization of its ECM [58-61].

The most striking result in the functional analysis obtained through CatWalk showed a greater intensity of the rats' paws' contact pressure during gait $24 \mathrm{~h}$ after transection, possibly due to the decrease of pain after treatment with the ADMSC associated with GDF- 5 in comparison to the control group. Treatment based on this association may have contributed to the reduction of acute inflammation and post-surgical edema, as well as decreased pain due to the reduction in the concentration of prostaglandins E2, nitric oxide activity, and reduction of free radicals [62]. These previously mentioned factors, although speculative, corroborate with the data of Forslund et al. [30], which showed that a single injection of GDF-5 during tendon repair decreased the inflammatory process, and with the data of Schneider et al. [17] that described immunomodulatory effects of the ADMSC.

The expression of 12 different genes related to inflammation, the remodeling of ECM, and the differentiation of ADMSC into tenocytes were studied to elucidate some molecular mechanisms involved in the repair of tendons. Our results demonstrated that ADMSC up-regulated the Dcn gene expression in comparison to other groups. The Dcn is a PG with a well-established structural function as it mediates the lateral fusion of collagen fibrils, contributing to the formation of mature collagen fiber with a larger diameter and, therefore, greater biomechanical resistance [63]. The lower expression of Din observed in the tendons treated with the ADMSC in association with GDF-5 may be directly related to the lower organization of the collagen fibers, resulting in lower biomechanical properties when compared to the control transected tendons, in relation to the ADMSC treated tendons. The application of ADMSC in association with GDF-5 also down-regulated the Lox gene expression compared to the ASC group, corroborating to the lower organization of collagen fibers in the ASC+GDF5 group. Herchenhan et al. [64] have demonstrated the direct role of Lox in collagen fibrilogenesis, showing that the inhibition of this enzyme activity harms the formation of the characteristic pattern of fibrils, leading to a decrease in the biomechanical resistance of tendon-like tissues constructed through bioengineering. It is worth mentioning that the Lox expression was higher after the treatment with ADMSC in comparison to the control transected tendon. It seems clear that there is a relation of the lower Gdf5 gene expression in the ASC+GDF5 group with the lower ECM organization and biomechanical parameters observed when compared to the ASC group [28-31].

Regarding the expression of genes related to tissue remodeling, Mmp2, Mmp8, Mmp9, and Timp2, higher expression of Mmp2 and Timp 2 was observed in the ASC group in relation only to the ASC+GDF5 group. The literature describes the increased expression and activity of these MMPs during tendon repair processes [8], since previous studies of our group showed a direct relationship between the greater activity of MMP-2 and greater organization of the ECM of tendons $[36,65,66]$, corroborating with the results from the present study. It is important to emphasize that the larger organization of the collagen fibers in the T1 region was also observed in the group treated with ADMSC only.

The application of ADMSC also up-regulated the Tgfb1 gene expression, another important gene whose expression modulates important processes during tendon repair. $T f b 1$ acts on the regulation of cell proliferation, differentiation, and migration, apoptosis, GAG deposition, and stimulates the production of collagen by fibroblasts [67-70], influencing the tissue healing cascade [71]. Tgfb1 is also involved in increased expression of tissue inhibitors of MMP (Timp) and Lox in different cell types, including in vitro fibroblasts [72], corroborating our results that showed a relation between the higher expression of $T g f b 1$, and increased expression of Lox and Timp2 after ADMSC application.

We observed a strong trend towards higher expression of the $S c x$ and Tnmd genes in tendons after ADMSC application in relation to the control group, supposing differentiation of ADMSC applied and/or endogenous stem cells into tenocytes. ADMSC have proven to modulate the host's "stem cell niche" by stimulating and recruiting endogenous stem cells to the injured site, promoting their differentiation [18]. $S c x$ has recently been reported as a marker of progenitor cell populations 
in tendons, being a transcription factor present in tendons from development to adulthood [73]. $S c x$ is a key regulator in the differentiation of tenocytes, whose expression is highly induced through the signaling pathway involving Tgfb1 [74], which was increased in the ASC group. According to Shukunami et al. [75], Scx positively regulates the expression of Tnmd, which is a transmembrane protein specifically expressed in dense connective tissues, such as tendons, ligaments, epimysium of skeletal muscle, cornea, and sclera [76-80], indicating the differentiation of ADMSC into tenocytes.

Our data showed the influence of the application of ADMSC isolated and in association with GDF- 5 in the expression of $50 \%$ of the analyzed genes, Dcn, Gdf5, Lox, Tgfb1, Mmp2, and Timp2. ADMSC in vitro presented, with exception of the Gdf5 gene, a similar gene expression profile of those five genes in comparison to the $S c x, T n m d, M m p 9$, Tnf, and Ilb1 genes. The literature describes that the ADMSC behavior seems to be modulated by the presence of molecules at the site where they are injected, such as cytokines, chemokines, peptides, and, mainly, growth factors $[67,68]$. Other studies also demonstrate the paracrine and immunomodulatory effects of ADMSC at the site of injury to promote tendon regeneration $[16,17]$.

In conclusion, the application of ADMSC up-regulated the Dcn, Lox, and Tgfb1 genes expression, which contributed to a higher collagen fiber organization and tendon biomechanics. The association of ADMSC with GDF-5 down-regulated the Dcn, Gdf5, Lox, Tgfb1, Mmp2, and Timp2, which contributed to an improvement of the rats' gait $24 \mathrm{~h}$ after the injury and impaired the organization and biomechanics of tendons. Although the literature describes the benefic effect of GDF- 5 for the tendon healing process, our results show that its application, isolated or associated with ADMSC, cannot improve the repair process of partial transected tendons, indicating the higher effectiveness of the application of ADMSC in injured Achilles tendons.

Author Contributions: Methodology, A.A.d.A., G.D.C., L.F.R.T., F.C.d.V., D.L.F., G.F.S., B.d.C.V. and E.R.P.; Formal Analysis, A.A.d.A., G.D.C., F.C.d.V., D.L.F., G.F.S., P.W.S., L.E.A., A.L.R.d.O., C.P.G., J.B.P., B.d.C.V., C.P.V. and E.R.P.; Resources, J.B.P. and M.A.M.E.; Writing-Original Draft Preparation, A.A.d.A., M.A.M.E., B.d.C.V. and E.R.P.; Writing-Review \& Editing, A.A.d.A. and E.R.P.; Supervision, E.R.P. and C.P.V.

Funding: This research was funded by FAPESP (Fundação de Amparo à Pesquisa do Estado de São Palulo), grant number 2012/14973-8.

Acknowledgments: The authors thank FAPESP for the financial support and for the fellowship awarded to A. A. de Aro (2012/14973-8).

Conflicts of Interest: The authors declare no conflict of interest.

\section{References}

1. Goncalves, A.I.; Rodrigues, M.T.; Lee, S.J.; Atala, A.; Yoo, J.J.; Reis, R.L.; Gomes, M.E. Understanding the role of growth factors in modulating stem cell tenogenesis. PLoS ONE 2013, 8, e83734. [CrossRef] [PubMed]

2. Zabrzynski, J.; Lapaj, L.; Paczesny, L.; Zabrzynska, A.; Grzanka, D. Tendon-function related structure, simple healing process and mysterious ageing. Folia Morphol. 2018. [CrossRef] [PubMed]

3. Vidal, B.C.; Mello, M.L. Proteoglycan arrangement in tendon collagen bundles. Cell Mol. Biol. 1984, 30, 195-204. [PubMed]

4. De Campos Vidal, B.; Mello, M.L. Optical anisotropy of collagen fibers of rat calcaneal tendons: An approach to spatially resolved supramolecular organization. Acta Histochem. 2010, 112, 53-61. [CrossRef] [PubMed]

5. Marqueti, R.C.; Durigan, J.L.Q.; Oliveira, A.J.S.; Mekaro, M.S.; Guzzoni, V.; Aro, A.A.; Pimentel, E.R.; Selistre-de-Araujo, H.S. Effects of aging and resistance training in rat tendon remodeling. FASEB $J$. 2018, 32, 353-368. [CrossRef] [PubMed]

6. Douglas, T.; Heinemann, S.; Bierbaum, S.; Scharnweber, D.; Worch, H. Fibrillogenesis of collagen types I, II, and III with small leucine-rich proteoglycans decorin and biglycan. Biomacromolecules 2006, 7, 2388-2393. [CrossRef] [PubMed]

7. Uysal, C.A.; Tobita, M.; Hyakusoku, H.; Mizuno, H. Adipose-derived stem cells enhance primary tendon repair: Biomechanical and immunohistochemical evaluation. J. Plast. Reconstr. Aesthet. Surg. 2012, 65, 1712-1719. [CrossRef] [PubMed] 
8. Oshiro, W.; Lou, J.; Xing, X.; Tu, Y.; Manske, P.R. Flexor tendon healing in the rat: A histologic and gene expression study. J. Hand Surg. Am. 2003, 28, 814-823. [CrossRef]

9. Tomiosso, T.C.; Nakagaki, W.R.; Gomes, L.; Hyslop, S.; Pimentel, E.R. Organization of collagen bundles during tendon healing in rats treated with L-NAME. Cell Tissue Res. 2009, 337, 235-242. [CrossRef] [PubMed]

10. Christiansen, D.L.; Huang, E.K.; Silver, F.H. Assembly of type I collagen: Fusion of fibril subunits and the influence of fibril diameter on mechanical properties. Matrix Biol. 2000, 19, 409-420. [CrossRef]

11. Almekinders, L.C.; Almekinders, S.V. Outcome in the treatment of chronic overuse sports injuries: A retrospective study. J. Orthop. Sports Phys. Ther. 1994, 19, 157-161. [CrossRef] [PubMed]

12. Favata, M.; Beredjiklian, P.K.; Zgonis, M.H.; Beason, D.P.; Crombleholme, T.M.; Jawad, A.F.; Soslowsky, L.J. Regenerative properties of fetal sheep tendon are not adversely affected by transplantation into an adult environment. J. Orthop. Res. 2006, 24, 2124-2132. [CrossRef] [PubMed]

13. Ni, M.; Lui, P.P.; Rui, Y.F.; Lee, Y.W.; Lee, Y.W.; Tan, Q.; Wong, Y.M.; Kong, S.K.; Lau, P.M.; Li, G.; et al. Tendon-derived stem cells (TDSCs) promote tendon repair in a rat patellar tendon window defect model. J. Orthop. Res. 2012, 30, 613-619. [CrossRef] [PubMed]

14. Pittenger, M.F.; Mackay, A.M.; Beck, S.C.; Jaiswal, R.K.; Douglas, R.; Mosca, J.D.; Moorman, M.A.; Simonetti, D.W.; Craig, S.; Marshak, D.R. Multilineage potential of adult human mesenchymal stem cells. Science 1999, 284, 143-147. [CrossRef] [PubMed]

15. Kern, S.; Eichler, H.; Stoeve, J.; Kluter, H.; Bieback, K. Comparative analysis of mesenchymal stem cells from bone marrow, umbilical cord blood, or adipose tissue. Stem Cells 2006, 24, 1294-1301. [CrossRef] [PubMed]

16. Okamoto, N.; Kushida, T.; Oe, K.; Umeda, M.; Ikehara, S.; Iida, H. Treating Achilles tendon rupture in rats with bone-marrow-cell transplantation therapy. J. Bone Joint Surg. Am. 2010, 92, 2776-2784. [CrossRef] [PubMed]

17. Schneider, M.; Angele, P.; Jarvinen, T.A.H.; Docheva, D. Rescue plan for Achilles: Therapeutics steering the fate and functions of stem cells in tendon wound healing. Adv. Drug Deliv. Rev. 2017, 129, 352-375. [CrossRef] [PubMed]

18. Gimble, J.M.; Katz, A.J.; Bunnell, B.A. Adipose-derived stem cells for regenerative medicine. Circ. Res. 2007, 100, 1249-1260. [CrossRef] [PubMed]

19. Park, A.; Hogan, M.V.; Kesturu, G.S.; James, R.; Balian, G.; Chhabra, A.B. Adipose-derived mesenchymal stem cells treated with growth differentiation factor-5 express tendon-specific markers. Tissue Eng. Part A 2010, 16, 2941-2951. [CrossRef] [PubMed]

20. Schneider, P.R.; Buhrmann, C.; Mobasheri, A.; Matis, U.; Shakibaei, M. Three-dimensional high-density co-culture with primary tenocytes induces tenogenic differentiation in mesenchymal stem cells. J. Orthop. Res. 2011, 29, 1351-1360. [CrossRef] [PubMed]

21. Pacini, S.; Spinabella, S.; Trombi, L.; Fazzi, R.; Galimberti, S.; Dini, F.; Carlucci, F.; Petrini, M. Suspension of bone marrow-derived undifferentiated mesenchymal stromal cells for repair of superficial digital flexor tendon in race horses. Tissue Eng. 2007, 13, 2949-2955. [CrossRef] [PubMed]

22. Vieira, M.H.; Oliveira, R.J.; Eca, L.P.; Pereira, I.S.; Hermeto, L.C.; Matuo, R.; Fernandes, W.S.; Silva, R.A.; Antoniolli, A.C. Therapeutic potential of mesenchymal stem cells to treat Achilles tendon injuries. Genet. Mol. Res. 2014, 13, 10434-10449. [CrossRef] [PubMed]

23. Valencia Mora, M.; Antuna Antuna, S.; Garcia Arranz, M.; Carrascal, M.T.; Barco, R. Application of adipose tissue-derived stem cells in a rat rotator cuff repair model. Injury 2014, 45 (Suppl. 4), S22-S27. [CrossRef]

24. Guilak, F.; Cohen, D.M.; Estes, B.T.; Gimble, J.M.; Liedtke, W.; Chen, C.S. Control of stem cell fate by physical interactions with the extracellular matrix. Cell Stem Cell 2009, 5, 17-26. [CrossRef] [PubMed]

25. Storm, E.E.; Huynh, T.V.; Copeland, N.G.; Jenkins, N.A.; Kingsley, D.M.; Lee, S.J. Limb alterations in brachypodism mice due to mutations in a new member of the TGF beta-superfamily. Nature 1994, 368, 639-643. [CrossRef] [PubMed]

26. Chang, S.C.; Hoang, B.; Thomas, J.T.; Vukicevic, S.; Luyten, F.P.; Ryba, N.J.; Kozak, C.A.; Reddi, A.H.; Moos, M., Jr. Cartilage-derived morphogenetic proteins. New members of the transforming growth factor-beta superfamily predominantly expressed in long bones during human embryonic development. J. Biol. Chem. 1994, 269, 28227-28234. [PubMed]

27. Zhou, S.; Yates, K.E.; Eid, K.; Glowacki, J. Demineralized bone promotes chondrocyte or osteoblast differentiation of human marrow stromal cells cultured in collagen sponges. Cell Tissue Bank. 2005, 6, 33-44. [CrossRef] [PubMed] 
28. Wolfman, N.M.; Hattersley, G.; Cox, K.; Celeste, A.J.; Nelson, R.; Yamaji, N.; Dube, J.L.; DiBlasio-Smith, E.; Nove, J.; Song, J.J. Ectopic induction of tendon and ligament in rats by growth and differentiation factors 5 , 6, and 7, members of the TGF-beta gene family. J. Clin. Investig. 1997, 100, 321-330. [CrossRef] [PubMed]

29. Forslund, C.; Aspenberg, P. Tendon healing stimulated by injected CDMP-2. Med. Sci. Sports Exerc. 2001,33, 685-687. [CrossRef] [PubMed]

30. Forslund, C.; Rueger, D.; Aspenberg, P. A comparative dose-response study of cartilage-derived morphogenetic protein (CDMP)-1, -2 and -3 for tendon healing in rats. J. Orthop. Res. 2003, 21, 617-621. [CrossRef]

31. Chhabra, A.; Tsou, D.; Clark, R.T.; Gaschen, V.; Hunziker, E.B.; Mikic, B. GDF-5 deficiency in mice delays Achilles tendon healing. J. Orthop. Res. 2003, 21, 826-835. [CrossRef]

32. Yang, X.F.; He, X.; He, J.; Zhang, L.H.; Su, X.J.; Dong, Z.Y.; Xu, Y.J.; Li, Y.; Li, Y.L. High efficient isolation and systematic identification of human adipose-derived mesenchymal stem cells. J. Biomed. Sci. 2011, 18, 59. [CrossRef] [PubMed]

33. Vidal, B.C. Form birefringence as applied to biopolymer and inorganic material supraorganization. Biotech. Histochem. 2010, 85, 365-378. [CrossRef] [PubMed]

34. Vidal, B.C.; Dos Anjos, E.H.; Mello, M.L. Optical anisotropy reveals molecular order in a mouse enthesis. Cell Tissue Res. 2015, 362, 177-185. [CrossRef] [PubMed]

35. Livak, K.J. Analyzing real-time PCR data by the comparative C(T) method. Nat. Protoc. 2008, 3, 1101-1108.

36. Aro, A.A.; Freitas, K.M.; Foglio, M.A.; Carvalho, J.E.; Dolder, H.; Gomes, L.; Vidal, B.C.; Pimentel, E.R. Effect of the Arrabidaea chica extract on collagen fiber organization during healing of partially transected tendon. Life Sci. 2013, 92, 799-807. [CrossRef] [PubMed]

37. Aro, A.A.; Perez, M.O.; Vieira, C.P.; Esquisatto, M.A.; Rodrigues, R.A.; Gomes, L.; Pimentel, E.R. Effect of Calendula officinalis cream on achilles tendon healing. Anat. Rec. 2015, 298, 428-435. [CrossRef] [PubMed]

38. Vidal, B.d.C. Evaluation of the carbohydrate role in the molecular order of collagen bundles: Microphotometric measurements of textural birefringence. Cell. Mol. Biol. 1986, 32, 527-535.

39. Feitosa, V.; Vidal, B.C.; Pimentel, E.R. Optical anisotropy of a pig tendon under compression. J. Anat. 2002, 200, 105-111. [CrossRef] [PubMed]

40. Mello, M.L.; de Campos Vidal, B. Experimental tendon repair: Glycosaminoglycan arrangement in newly synthesized collagen fibers. Cell. Mol. Biol. (Noisy-le-grand) 2003, 49, 579-585.

41. Stegemann, H.; Stalder, K. Determination of hydroxyproline. Clin. Chim. Acta 1967, 18, 267-273. [CrossRef]

42. Biancalana, A.; Veloso, L.A.; Gomes, L. Obesity affects collagen fibril diameter and mechanical properties of tendons in Zucker rats. Connect. Tissue Res. 2010, 51, 171-178. [CrossRef] [PubMed]

43. Sparrow, K.J.; Finucane, S.D.; Owen, J.R.; Wayne, J.S. The effects of low-intensity ultrasound on medial collateral ligament healing in the rabbit model. Am. J. Sports Med. 2005, 33, 1048-1056. [CrossRef] [PubMed]

44. Yang, X.; Liang, L.; Zong, C.; Lai, F.; Zhu, P.; Liu, Y.; Jiang, J.; Yang, Y.; Gao, L.; Ye, F.; et al. Kupffer cells-dependent inflammation in the injured liver increases recruitment of mesenchymal stem cells in aging mice. Oncotarget 2016, 7, 1084-1095. [CrossRef] [PubMed]

45. Heissig, B.; Dhahri, D.; Eiamboonsert, S.; Salama, Y.; Shimazu, H.; Munakata, S.; Hattori, K. Role of mesenchymal stem cell-derived fibrinolytic factor in tissue regeneration and cancer progression. Cell. Mol. Life Sci. 2015, 72, 4759-4770. [CrossRef] [PubMed]

46. Parry, D.A. The molecular and fibrillar structure of collagen and its relationship to the mechanical properties of connective tissue. Biophys. Chem. 1988, 29, 195-209. [CrossRef]

47. Birk, D.E.; Mayne, R. Localization of collagen types I, III and V during tendon development. Changes in collagen types I and III are correlated with changes in fibril diameter. Eur. J. Cell Biol. 1997, 72, 352-361. [PubMed]

48. Oryan, A.; Moshiri, A. A long term study on the role of exogenous human recombinant basic fibroblast growth factor on the superficial digital flexor tendon healing in rabbits. J. Musculoskelet. Neuronal Interact. 2011, 11, 185-195. [PubMed]

49. Del Bue, M.; Ricco, S.; Ramoni, R.; Conti, V.; Gnudi, G.; Grolli, S. Equine adipose-tissue derived mesenchymal stem cells and platelet concentrates: Their association in vitro and in vivo. Vet. Res. Commun. 2008, 32 (Suppl. 1), S51-S55. [CrossRef] [PubMed]

50. Uysal, A.C.; Mizuno, H. Differentiation of adipose-derived stem cells for tendon repair. Methods Mol. Biol. 2011, 702, 443-451. [PubMed] 
51. Bolt, P.; Clerk, A.N.; Luu, H.H.; Kang, Q.; Kummer, J.L.; Deng, Z.L.; Olson, K.; Primus, F.; Montag, A.G.; He, T.C. BMP-14 gene therapy increases tendon tensile strength in a rat model of Achilles tendon injury. J. Bone Joint Surg. Am. 2007, 89, 1315-1320. [CrossRef] [PubMed]

52. Mikic, B.; Schalet, B.J.; Clark, R.T.; Gaschen, V.; Hunziker, E.B. GDF-5 deficiency in mice alters the ultrastructure, mechanical properties and composition of the Achilles tendon. J. Orthop. Res. 2001, 19, 365-371. [CrossRef]

53. Rickert, M.; Wang, H.; Wieloch, P.; Lorenz, H.; Steck, E.; Sabo, D.; Richter, W. Adenovirus-mediated gene transfer of growth and differentiation factor- 5 into tenocytes and the healing rat Achilles tendon. Connect. Tissue Res. 2005, 46, 175-183. [CrossRef] [PubMed]

54. Chan, B.P.; Chan, K.M.; Maffulli, N.; Webb, S.; Lee, K.K. Effect of basic fibroblast growth factor. An in vitro study of tendon healing. Clin. Orthop. Relat. Res. 1997, 239-247. [CrossRef]

55. McGeachie, J.; Tennant, M. Growth factors and their implications for clinicians: A brief review. Aust. Dent. J. 1997, 42, 375-380. [CrossRef] [PubMed]

56. Sharma, P.; Maffulli, N. Tendon injury and tendinopathy: Healing and repair. J. Bone Joint Surg. Am. 2005, 87, 187-202. [PubMed]

57. Sheng, J.; Zeng, B.; Jiang, P. Effects of exogenous basic fibroblast growth factor on in-sheathed tendon healing and adhesion formation. Zhongguo xiu fu chong jian wai ke za zhi Chin. J. Reparative Reconstr. Surg. 2007, 21, 733-737.

58. Gospodarowicz, D.; Ferrara, N.; Schweigerer, L.; Neufeld, G. Structural characterization and biological functions of fibroblast growth factor. Endocr. Rev. 1987, 8, 95-114. [CrossRef] [PubMed]

59. McNeil, P.L.; Muthukrishnan, L.; Warder, E.; D'Amore, P.A. Growth factors are released by mechanically wounded endothelial cells. J. Cell Biol. 1989, 109, 811-822. [CrossRef] [PubMed]

60. Kannus, P. Structure of the tendon connective tissue. Scand. J. Med. Sci. Sports 2000, 10, 312-320. [CrossRef] [PubMed]

61. Wurgler-Hauri, C.C.; Dourte, L.M.; Baradet, T.C.; Williams, G.R.; Soslowsky, L.J. Temporal expression of 8 growth factors in tendon-to-bone healing in a rat supraspinatus model. J. Shoulder Elb. Surg. 2007, 16, S198-S203. [CrossRef] [PubMed]

62. Hu, C.; Ding, Y.; Chen, J.; Liu, D.; Ding, M.; Zhang, Y. Treatment of corneal epithelial wounds in dogs using basic fibroblast growth factor. Vet. Med. (Praha) 2009, 54, 280-286. [CrossRef]

63. Dunkman, A.A.; Buckley, M.R.; Mienaltowski, M.J.; Adams, S.M.; Thomas, S.J.; Satchell, L.; Kumar, A.; Pathmanathan, L.; Beason, D.P.; Iozzo, R.V.; et al. The tendon injury response is influenced by decorin and biglycan. Ann. Biomed. Eng. 2013, 42, 619-630. [CrossRef] [PubMed]

64. Herchenhan, A.; Uhlenbrock, F.; Eliasson, P.; Weis, M.; Eyre, D.; Kadler, K.E.; Magnusson, S.P.; Kjaer, M. Lysyl Oxidase Activity Is Required for Ordered Collagen Fibrillogenesis by Tendon Cells. J. Biol. Chem. 2015, 290, 16440-16450. [CrossRef] [PubMed]

65. Aro, A.A.; Nishan, U.; Perez, M.O.; Rodrigues, R.A.; Foglio, M.A.; Carvalho, J.E.; Gomes, L.; Vidal, B.C.; Pimentel, E.R. Structural and biochemical alterations during the healing process of tendons treated with Aloe vera. Life Sci. 2012, 91, 885-893. [CrossRef] [PubMed]

66. Lee, C.; An, J.; Kim, J.H.; Kim, E.S.; Kim, S.H.; Cho, Y.K.; Cha, D.H.; Han, M.Y.; Lee, K.H.; Sheen, Y.H. Low levels of tissue inhibitor of metalloproteinase-2 at birth may be associated with subsequent development of bronchopulmonary dysplasia in preterm infants. Korean J. Pediatr. 2015, 58, 415-420. [CrossRef] [PubMed]

67. Van Buul, G.M.; Villafuertes, E.; Bos, P.K.; Waarsing, J.H.; Kops, N.; Narcisi, R.; Weinans, H.; Verhaar, J.A.; Bernsen, M.R.; van Osch, G.J. Mesenchymal stem cells secrete factors that inhibit inflammatory processes in short-term osteoarthritic synovium and cartilage explant culture. Osteoarthritis Cartil. 2012, 20, 1186-1196. [CrossRef] [PubMed]

68. Manferdini, C.; Maumus, M.; Gabusi, E.; Piacentini, A.; Filardo, G.; Peyrafitte, J.A.; Jorgensen, C.; Bourin, P.; Fleury-Cappellesso, S.; Facchini, A. Adipose-derived mesenchymal stem cells exert antiinflammatory effects on chondrocytes and synoviocytes from osteoarthritis patients through prostaglandin E2. Arthritis Rheum. 2013, 65, 1271-1281. [CrossRef] [PubMed]

69. Molloy, T.; Wang, Y.; Murrell, G. The roles of growth factors in tendon and ligament healing. Sports Med. 2003, 33, 381-394. [CrossRef] [PubMed]

70. Fu, S.C.; Wong, Y.P.; Cheuk, Y.C.; Lee, K.M.; Chan, K.M. TGF-beta1 reverses the effects of matrix anchorage on the gene expression of decorin and procollagen type I in tendon fibroblasts. Clin. Orthop. Res. 2005, 226-232. [CrossRef] 
71. Mehta, V.; Mass, D. The use of growth factors on tendon injuries. J. Hand Ther. 2005, 18, 87-92; quiz 93. [CrossRef] [PubMed]

72. Finnson, K.W.; McLean, S.; Di Guglielmo, G.M.; Philip, A. Dynamics of Transforming Growth Factor Beta Signaling in Wound Healing and Scarring. Adv. Wound Care 2013, 2, 195-214. [CrossRef] [PubMed]

73. Schweitzer, R.; Chyung, J.H.; Murtaugh, L.C.; Brent, A.E.; Rosen, V.; Olson, E.N.; Lassar, A.; Tabin, C.J. Analysis of the tendon cell fate using Scleraxis, a specific marker for tendons and ligaments. Development 2001, 128, 3855-3866. [PubMed]

74. Holladay, C.; Abbah, S.A.; O'Dowd, C.; Pandit, A.; Zeugolis, D.I. Preferential tendon stem cell response to growth factor supplementation. J. Tissue Eng. Regen. Med. 2016, 10, 783-798. [CrossRef] [PubMed]

75. Shukunami, C.; Takimoto, A.; Oro, M.; Hiraki, Y. Scleraxis positively regulates the expression of tenomodulin, a differentiation marker of tenocytes. Dev. Biol. 2006, 298, 234-247. [CrossRef] [PubMed]

76. Brandau, O.; Meindl, A.; Fassler, R.; Aszodi, A. A novel gene, tendin, is strongly expressed in tendons and ligaments and shows high homology with chondromodulin-I. Dev. Dyn. 2001, 221, 72-80. [CrossRef] [PubMed]

77. Shukunami, C.; Oshima, Y.; Hiraki, Y. Molecular cloning of tenomodulin, a novel chondromodulin-I related gene. Biochem. Biophy. Res. Commun. 2001, 280, 1323-1327. [CrossRef] [PubMed]

78. Yamana, K.; Wada, H.; Takahashi, Y.; Sato, H.; Kasahara, Y.; Kiyoki, M. Molecular cloning and characterization of CHM1L, a novel membrane molecule similar to chondromodulin-I. Biochem. Biophy. Res. Commun. 2001, 280, 1101-1106. [CrossRef] [PubMed]

79. Oshima, Y.; Shukunami, C.; Honda, J.; Nishida, K.; Tashiro, F.; Miyazaki, J. Chondromodulin-I-related angiogenesis inhibitor, in mouse eyes. Investig. Ophthalmol. Vis. Sci. 2003, 44, 1814-1823. [CrossRef]

80. Pisani, D.F.; Pierson, P.M.; Massoudi, A.; Leclerc, L.; Chopard, A.; Marini, J.F.; Dechesne, C.A. Myodulin is a novel potential angiogenic factor in skeletal muscle. Exp. Cell Res. 2004, 292, 40-50. [CrossRef] [PubMed]

(C) 2018 by the authors. Licensee MDPI, Basel, Switzerland. This article is an open access article distributed under the terms and conditions of the Creative Commons Attribution (CC BY) license (http:/ / creativecommons.org/licenses/by/4.0/). 